\title{
A review of the taxonomy and relationships of the Dendrobium speciosum complex (Orchidaceae), and recognition of two new taxa
}

\author{
Peter B. Adams, Jacinta M. Burke and Sheryl D. Lawson
}

The School of Botany, University of Melbourne, Victoria, Australia 3010

\begin{abstract}
Dendrobium speciosum is one of Australia's most prominent orchids. Two hundred years after the type description, there are several contrasting taxonomic treatments of the D. speciosum complex. We review the taxonomy from first descriptions and incorporate recent numerical approaches. Our explorations extend the plant range to an almost continuous distribution along the east coast of Australia, with disjunct populations along the Tropic of Capricorn. Data from field observations, and studies of 453 plants over the entire distribution range were analysed using morphological and multivariate techniques. Results indicate a species complex forming a continuum of variation. Within the continuum from north to south the varieties boreale, pedunculatum, curvicaule, capricornicum, grandiflorum, hillii and speciosum occupy geographical areas which are defined approximately, and they exhibit significant infra-varietal variation. At interfaces of described varieties, populations show intermediate characteristics. There are no distinct qualitative differences in characters between any of the varieties or groups. We describe two new varieties, var. blackdownense and var. carnarvonense from central Queensland and propose that var. capricornicum Clemesha be retained for plants of east Capricorn.
\end{abstract}

\section{Introduction}

Dendrobium speciosum Sm. is one of Australia's most outstanding, widespread, and variable orchids. The complexity of variation has been highlighted by Burke (1998) and Burke and Adams (2002) using numerical analytical methods. They interpreted the complex as consisting of intergrading varieties, with some forms that could not be ascribed to any distinct groups. Nonetheless, taxa can be identified and treated as varieties. In very confusing populations along the Tropic of Capricorn, a detailed study of north Queensland plants resulted in the description of a new variety, var. boreale, and establishment of a neotype (and narrowed re-circumscription) for plants of var. curvicaule, which occurs between St Lawrence and Mt Dryander (Adams et al. 2006a).

Detailed field work from eastern Victoria to far north Queensland and west to Carnarvon Gorge has led to a reappraisal of the species and its taxonomy, defining the limits of taxa in relation to habitat and latitude. In this study we analyse a data set from all areas, 
including plants from recently explored remote areas not previously known to contain D. speciosum. We review taxonomic approaches and the currently defined varieties and geographically defined groups, which are compared in relation to the complex.

\section{Historical review}

Dendrobium speciosum was described by Smith (1804), and the type specimen is held in the Linnaean herbarium at the Linnaean Society in London (LINN). 'Port Jackson New South Wales' is written on the type sheet and the following is a transcription of the original description.

\section{"DENDROBIUM speciosum Great Dendrobium}

GYNANDRIA Diandria

"Nectary a lip without a spur. Petals 5; the 2 lower external ones forming a pouch with their base. Lid vertical.

"Flowers often reversed. Cluster solitary, many-flowered. Lip three-lobed. Leaves radical, coriaceous.

Dendrobium speciosum var. hillii was described by Masters in 1877 (having been described previously at species rank as D. hillii by Sir William Hooker in 1861), followed by var. curvicaule and var. grandiflorum (Bailey 1896). The original descriptions are not sufficiently diagnostic to distinguish the varieties in question from other members of this complex. The varieties established in the nineteenth century were based on a few specimens, and as new areas of distribution were examined the range of morphological variation was found to be far greater than initially appreciated, blurring distinctions between some varieties. This has led to questions about the taxonomic rank of these variants (Clemesha 1982). Since Dockrill's first book in 1969 there have been reviews by several authors (Clemesha 1981a, 1981b, 1986, Clements 1989, Banks \& Clemesha 1990, Adams 1991), with limited new evidence offered.

Dockrill (1969) initially recognised five varieties: var. speciosum, var. hillii Mast., var. grandiflorum F.M.Bailey, var. curvicaule F.M.Bailey and var. nitidum F.M.Bailey. Clemesha (1981a, 1986) reviewed the described varieties, reproduced original descriptions, photographs of type specimens, photocopies of plants typical of varieties, and commented on atypical forms and variation in central Queensland, without making categorical statements about taxonomic rank. He also described a new variety, var. pedunculatum, from the Atherton area of north Queensland (Clemesha 1981a). He regarded the central Queensland plants, and plants at Byfield and west at Carnarvon Gorge, as dwarf races of var. grandiflorum. In 1982, Clemesha described a new variety, var. capricornicum, from the volcanic plug of Mt Jim Crow, near Rockhampton in Central Queensland, and considered that plants at Blackdown Tableland and Carnarvon Gorge represented different colour forms of this variety. Plants from different habitats close to the plugs were noted to differ from typical var. capricornicum in some characters.

The six varieties of $D$. speciosum recognised by Dockrill (1992) were D. speciosum var. speciosum (Smith 1804), D. speciosum var. hillii (Masters 1877), D. speciosum var. grandiflorum (Bailey 1896), D. speciosum var. curvicaule (Bailey 1896), D. speciosum var. pedunculatum (Clemesha 1981), and D. speciosum var. capricornicum (Clemesha 1982). Dendrobium speciosum var. nitidum F.M.Bailey, D. x nitidum (F.M.Bailey) 
M.A.Clem. \& D.L.Jones, D. speciosum var. bancroftianum Rchb.f., and D. jonesii Rendle subsp. bancroftianum (Rchb.f.) M.A.Clem. \& D.L.Jones are now considered to represent D. $\mathrm{x}$ gracillimum, a natural hybrid between $D$. speciosum and D. gracilicaule (Clemesha 1981a, Banks \& Clemesha 1990).

Jones (1988) treated D. speciosum as having six varieties. Upton (1989) recognised 'an extremely variable species' of six varieties: var. speciosum, var. hillii, var. grandiflorum, var. capricornicum, var. curvicaule and var. pedunculatum. Clements (1989) raised these varieties to species rank, with the exception of var. capricornicum, which was subsumed under D. curvicaule. Clements defined his species concept as one or more significant and consistent differences in characters, and described differences for each proposed species that have not been supported by any published studies. The changes have not been accepted by subsequent taxonomic reviewers (Banks \& Clemesha 1990; Grundon et al. 1990; Adams 1991; Lavarack 1991; Dockrill 1992, 1995).

Banks and Clemesha (1990), in rejecting Clements' taxonomic treatment, regarded var. speciosum, var. hillii, var. grandiflorum, var. curvicaule, var. pedunculatum and var. capricornicum as subspecies, noting that some shared the same habitat, and intermediate forms were present. Reasons for proposing the rank of subspecies were not offered. In his revised Australian Indigenous Orchids in 1992, Dockrill recognised six varieties, and a degree of overlap, stating that his attempt at developing a key could not separate all plants into distinct varieties. Lavarack and Gray (1985) also accorded the taxa varietal rank. Adams (1991) provided a review of variation, pollination and breeding systems in D. speciosum, and recommended the retention of six varieties that were not completely distinct, with overlapping habitat, and variable, inconsistent features.

All reviews suggested separate distributions for the varieties, with large gaps, especially in dry areas between Rockhampton and Mackay, and around Townsville. Since then the range of known forms, localities and distribution has progressively extended. The following deficiencies are evident in past treatments: insufficient sampling of regions using living material, errors in distributions, assumptions of gaps in distribution in dry and inaccessible habitat, lack of published data to support conclusions and taxonomic proposals, and a strong tendency to place all plants into distinct taxonomic groups, whether at species, subspecies or varietal rank, even when their characteristics do not correspond with the circumscription of taxa. Clements (1989) used character differences including aerial roots, pseudobulb shape, floral segments, labellar notches, and breeding biology to propose separate species. The use of these characters for diagnosis has been refuted (Banks \& Clemesha 1990, Adams 1991, Dockrill 1992, Burke \& Adams 2002). In view of the large distribution range and variability, these problems are understandable, but have led to considerable confusion.

Subsequent numerical approaches (Burke 1998, Burke \& Adams 2002) have supported the concept of a species complex, which required further survey and analysis. We have published new distributional data, undertaken numerical analyses in all regions, and described a new variety, var. boreale which applies to rainforest plants north of Townsville that had previously been included in var. curvicaule. We have also respecified the range of occurrence of neotypified var. curvicaule (Adams et al. 2006a) (Table 1). 
Table 1. Recent classifications of Dendrobium speciosum.

\begin{tabular}{|c|c|c|c|c|}
\hline Clements 1989 & $\begin{array}{l}\text { Banks and } \\
\text { Clemesha } 1990\end{array}$ & Adams 1991 & Dockrill 1992 & $\begin{array}{l}\text { Adams et al. } \\
2006 a\end{array}$ \\
\hline D. speciosum & subsp. speciosum & var. speciosum & var. speciosum & var. speciosum \\
\hline D. tarberi & subsp. hillii & var. hillii & var. hillii & var. hillii \\
\hline D. rex & subsp. grandiflorum & var. grandiflorum & var. grandiflorum & var. grandiflorum \\
\hline D. curvicaule & subsp. capricornicum & var. capricornicum & var. capricornicum & var. capricornicum \\
\hline D. curvicaule & subsp. curvicaule & var. curvicaule & var. curvicaule & $\begin{array}{l}\text { var. curvicaule, } \\
\text { var. boreale }\end{array}$ \\
\hline D. pedunculatum & subsp. pedunculatum & var. pedunculatum & var. pedunculatum & var. pedunculatum \\
\hline
\end{tabular}

We have now analysed our entire data set for D. speciosum to extend our understanding of the species and to test previous taxonomic recommendations (Burke \& Adams 2002).

\section{Materials and methods}

\section{Sampling}

Specimens were collected during field trips conducted in all regions during the flowering season (May to September) between 1981 and 2005. Populations studied represented the variation throughout each geographic area. In each study population, 6-12 plants were sampled to encompass the major variation in plant and floral characteristics. The following numbers of individuals were used in the analyses for the regions depicted in Fig. 1: Region 1a-39 plants, Region 1b-37 plants, Region 2-35 plants, Region 3-13 plants, Region 4-25 plants, Region 5-43 plants, Region 6-46 plants, Regions 7 and 8-52 plants. Wherever possible measurements were made in the field, otherwise samples were taken by removing a small number of pseudobulbs, together with roots, from the side of the plant to minimise damage and prevent local depletion. All plants were then grown in aged pine park in raised beds or pots under greenhouse conditions.

A reference collection of the sampled plants, photographic library and pressed floral parts have been maintained, as fully representative herbarium specimens of such large plants are not practical. Four hundred and fifty three plants were measured. Voucher details (including locations) of these plants can be obtained by contacting the Queensland Herbarium and the National Herbarium of Victoria. Dendrobium speciosum is under heavy pressure from illegal collecting, and thus no specific locality information is provided here.

Seventy-two characters were used to assess variation in the D. speciosum complex. Thirty-three characters were subsequently considered to be of taxonomic value (Table 2) and used in univariate and multivariate analyses. 
Table 2. Morphological characters used in analyses for variation within and between populations of Dendrobium speciosum.

\section{Vegetative characters}

1. Pseudobulb length $(\mathrm{cm})$

2. Pseudobulb width at base $(\mathrm{cm})$

3. Pseudobulb width at midpoint $(\mathrm{cm})$

4. Pseudobulb width at top $(\mathrm{cm})$

5. Number of internodes in pseudobulb

6. Collum (narrowing of pseudobulb above swollen base) $0=$ absent, $1=0.5-<1.0 \mathrm{~cm}$ long, $2=1.0-2.0 \mathrm{~cm}$ long, $3=>2.0 \mathrm{~cm}$ long

7. Number of leaves

8. Leaf length $(\mathrm{cm})$

9. Leaf width $(\mathrm{cm})$

10. Leaf thickness $(\mathrm{mm})$

11. Aerial roots $0=$ nil, $1=1-3$ per 10 pseudobulbs, $2=4-25$ per 10 pseudobulbs (roots usually $>10 \mathrm{~cm}$ in height), $3=>25$ per 10 pseudobulbs (roots usually erect and $>30 \mathrm{~cm}$ in height)

\section{Floral characters}

12. Number of flowers

13. Rachis length $(\mathrm{cm})$

14. Peduncle length $(\mathrm{cm})$

15. Peduncle width $(\mathrm{mm})$

16. Flower length (dorsal sepal tip-lateral sepal tips) (cm)

17. Flower length (dorsal sepal tip-mentum) $(\mathrm{cm})$

18. Flower width across petals (flattened) $(\mathrm{cm})$

19. Flower width at mentum (flattened) $(\mathrm{cm})$

20. Dorsal sepal length $(\mathrm{cm})$

21. Dorsal sepal width at base $(\mathrm{cm})$

22. Petal length $(\mathrm{cm})$

23. Petal width at base $(\mathrm{mm})$

24. Individual lateral sepal width at base $(\mathrm{cm})$

25. Width of lateral sepals at widest point (flattened) $(\mathrm{cm})$

26. Distance between lateral sepal tips (flattened) $(\mathrm{cm})$

27. Inner width of lateral sepals at widest point (flattened) $(\mathrm{cm})$

28. Distance from base of lateral sepals to their tips $(\mathrm{cm})$

29. Pedicel length $(\mathrm{cm})$

30. Midlobe length $(\mathrm{cm})$

31. Midlobe width $(\mathrm{cm})$

32. Forelobe ${ }^{A}$ length $(\mathrm{cm})$

33. Forelobe width $(\mathrm{cm})$

${ }^{A}$ Forelobe $=$ lateral lobes plus lamina

Morphological data were collected from the 453 specimens. Specimens were coded according to their region (Fig. 1) to facilitate discussion and the formation of hypotheses. Individuals were allocated into regions on the basis of latitude, distribution ranges of taxa previously circumscribed, and additional distribution from recent exploration. A total of 281 individuals were used for the multivariate analyses in this study using random sampling from the larger data set of 453 plants, so that all regions were adequately represented in relation to their geography and extent of variation. 
An attempt was made to use pickled and prepared specimens already available or prepared from our initial surveys. This method was abandoned as the material did not preserve well and many of the characters of Table 2 could not be accurately assessed.

Therefore fresh living material was used for all measurements. For each specimen, measurements were made on three representative organs where possible, and the mean value used for analyses. The first leaf from the base of the pseudobulb was used for all leaf measurements. In the few cases where it was not possible to obtain three measurements, due to damaged or missing parts, mean values were calculated from the available material.

\section{Phenetic analysis}

Morphological data were range standardised, and a Manhattan Metric (MM) distance matrix (Sneath and Sokal 1973, Milligan and Cooper 1988) was calculated. The data set was subjected to numerical pattern analysis using the PATN package (Belbin 1988). For cluster analysis, the unweighted pair-group arithmetic averaging (UPGMA) was used. A cluster intensity co-efficient $(\beta=-0.25)$ was chosen because this setting is spacedilating, and affords maximum opportunity to separate subgroups. It sharpens any discontinuities in the system so that clustering is intensified (Williams 1975a). It is particularly useful when it is suspected that no sharp discontinuities exist in the data, and it may reveal unsuspected groupings. Cramer values were calculated as previously (Burke \& Adams 2002) to determine which characters best discriminated the final groups identified.

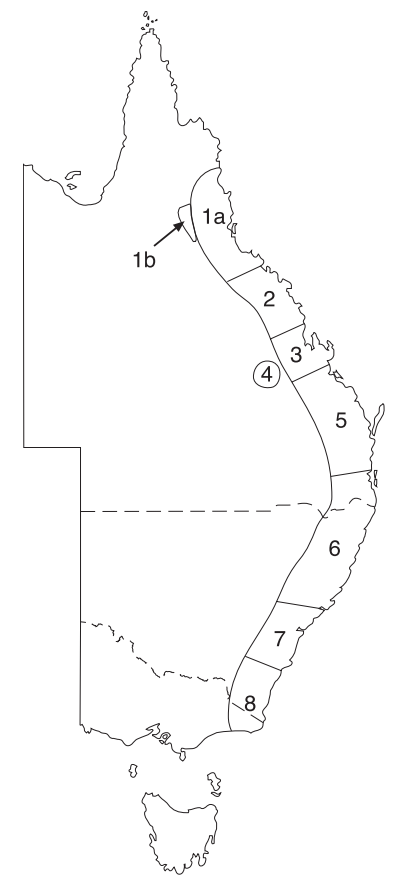

Fig. 1. Distribution range of $D$. speciosum species complex showing regions defined for this study. 
The distance matrix was used for ordination by principal coordinates analysis (PCoA) (Gower 1966). Ordination techniques are considered more appropriate for analysis at the population level because, unlike cluster analysis, they do not assume a hierarchical pattern of relationships, which may not be present at the infra-specific level (Gould \& Johnston 1972, Crisp \& Weston 1993). Character vectors and their correlation coefficients were determined to allow examination of trends of characters across the ordination space (Williams 1975b, Belbin 1988).

\section{Variation of characters within and between taxa}

Maximum, minimum and mean values, and first to third interquartile ranges were calculated for pseudobulb, leaf and flower length for plants in Regions 1-8 of Fig. 1.

\section{Results}

\section{Cluster analysis combining vegetative and floral characters}

Nine groups were identified in the UPGMA classification, seven containing a mix of plants from different regions or representing different varieties (Fig. 2, Table 3).

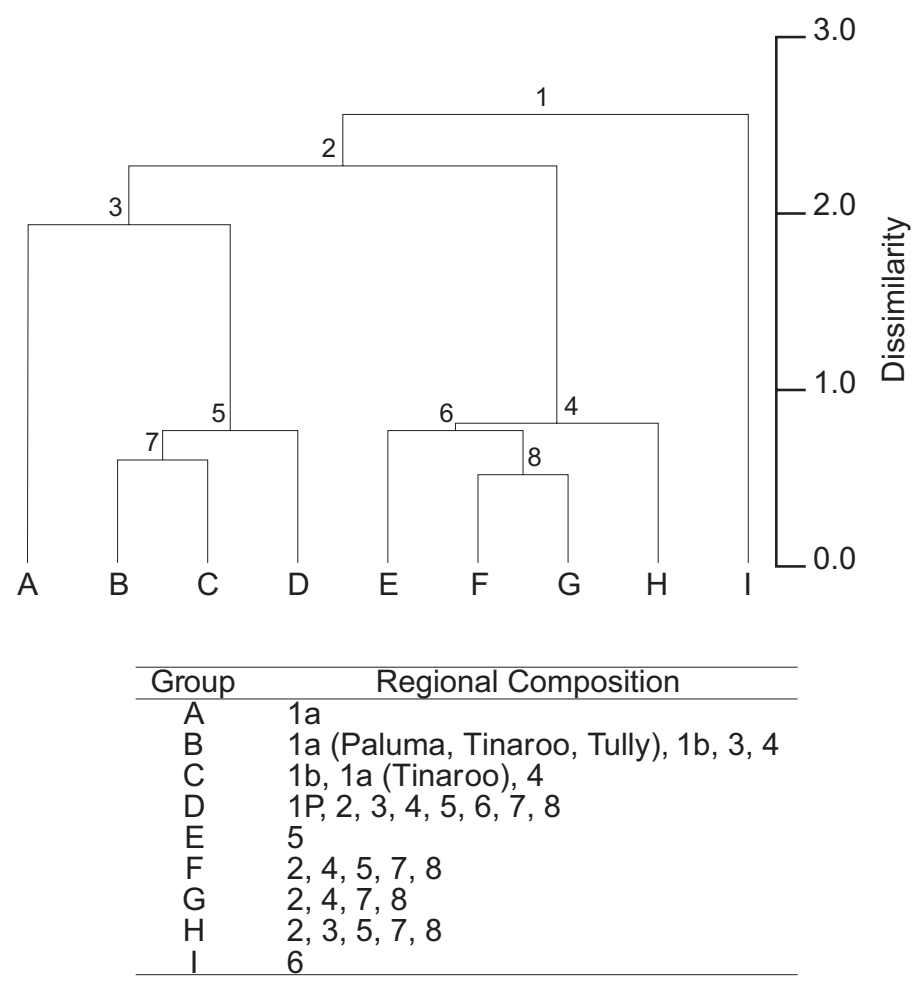

Fig. 2. Classification (UPGMA, $\beta=-0.25$ ) of D. speciosum individuals throughout the distribution range using vegetative and floral morphological characters truncated at nine groups. 
Table 3. Cramer values for the most important characters of each dichotomy in the classification of $D$. speciosum individuals from throughout the distribution range based on vegetative and floral morphological characters (UPGMA $\beta=-0.25$ ).

\begin{tabular}{|c|c|c|}
\hline Dichotomy & Character Number and Character & Cramer Value \\
\hline \multirow[t]{2}{*}{1} & 33. Forelobe width & 0.6926 \\
\hline & 31. Midlobe width & 0.6694 \\
\hline \multirow[t]{5}{*}{2} & 18. Flower width across petals (flattened) & 0.7793 \\
\hline & 16. Flower length (dorsal sepal tip-lateral sepal tips) & 0.7666 \\
\hline & 20. Dorsal sepal length & 0.7658 \\
\hline & 22. Petal length & 0.7600 \\
\hline & 28. Distance from base of lateral sepals to their tips & 0.6961 \\
\hline \multirow[t]{3}{*}{3} & 6. Collum & 0.8331 \\
\hline & 1. Pseudobulb length & 0.6746 \\
\hline & 9. Leaf width & 0.6584 \\
\hline \multirow[t]{4}{*}{4} & 24. Individual lateral sepal width at base & 0.7591 \\
\hline & 25. Width of the lateral sepals at widest point (flattened) & 0.7328 \\
\hline & 21. Dorsal sepal width at base & 0.7132 \\
\hline & 25. Width of lateral sepals at widest point (flattened) & 0.6702 \\
\hline \multirow[t]{5}{*}{5} & 28. Distance from base of lateral sepals to their tips & 0.7621 \\
\hline & 14. Peduncle length & 0.7393 \\
\hline & 5. Number internodes in pseudobulb & 0.6841 \\
\hline & 15. Peduncle width & 0.6713 \\
\hline & 8. Leaf length & 0.6501 \\
\hline \multirow[t]{3}{*}{6} & 1. Pseudobulb length & 0.7801 \\
\hline & 12. Number of flowers & 0.7514 \\
\hline & 7. Number of leaves & 0.6601 \\
\hline \multirow[t]{5}{*}{7} & 22. Petal length & 0.8327 \\
\hline & 24. Individual lateral sepal width at base & 0.8134 \\
\hline & 28. Distance from base of lateral sepals to their tips & 0.7935 \\
\hline & 21. Dorsal sepal width at base & 0.7628 \\
\hline & 23. Petal width at base & 0.7429 \\
\hline \multirow[t]{4}{*}{8} & 18. Flower width across petals (flattened) & 0.8744 \\
\hline & 16. Flower length (dorsal sepal tip-lateral sepal tips) & 0.8720 \\
\hline & 22. Petal length & 0.8612 \\
\hline & 20. Dorsal sepal length & 0.8665 \\
\hline
\end{tabular}

The first dichotomy separated Group I, representing most, but not all, plants of var. hillii (or plants from Region 6). The second dichotomy separated the mixed Groups E, F, G, and H from mixed Groups B, C, D, and Group A, which represents rainforest plants north of Townsville. Some north Queensland plants of shorter stature were clustered in Groups B and C. While Cramer values for most floral and the collum characters were moderately high $(>0.8)$, their values indicate that there is still considerable overlap between the groups formed at the eighth dichotomy. The remaining characters had low to moderate Cramer values, indicating considerable overlap in character values between the groups formed at this level. 


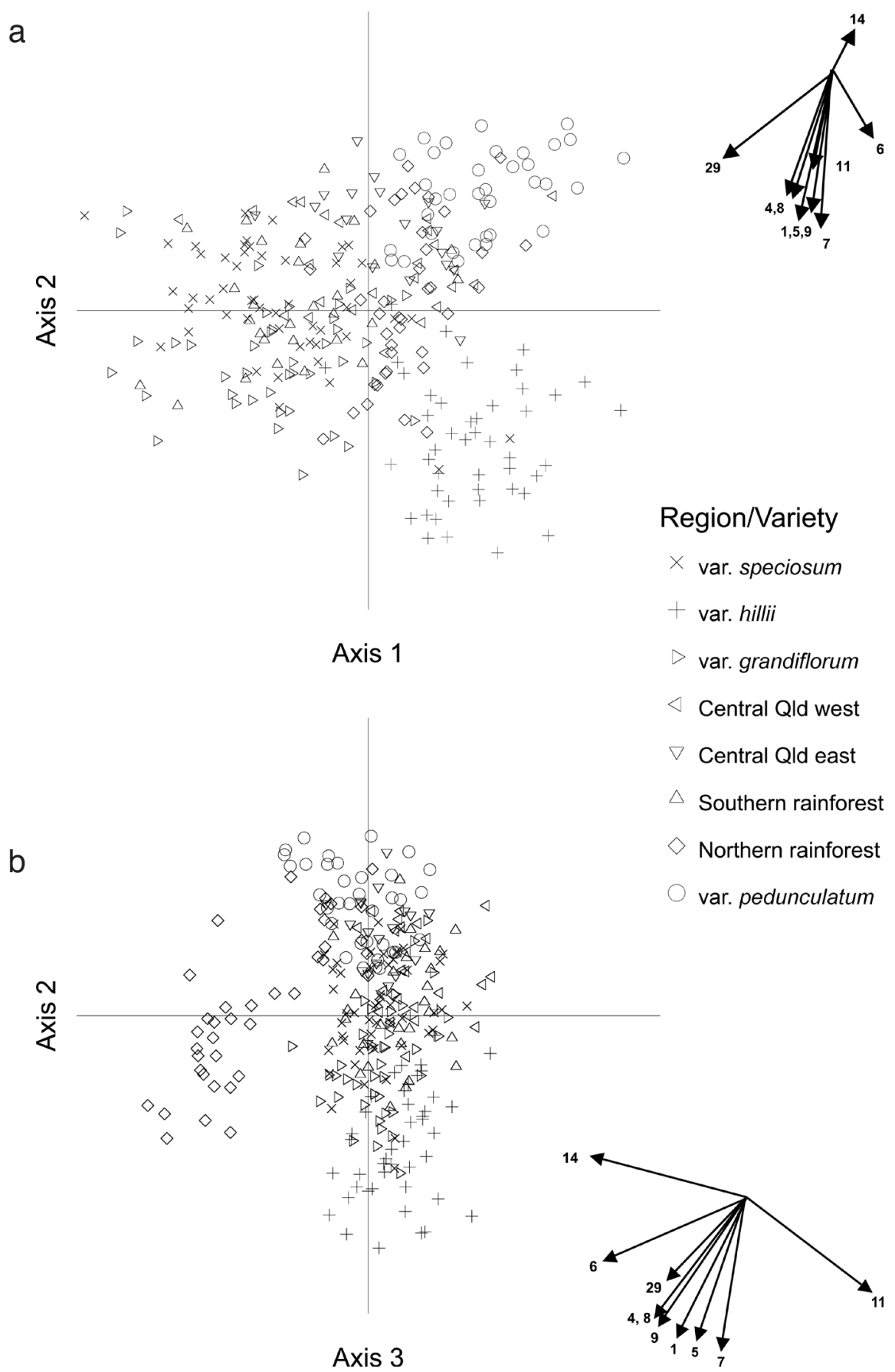

Fig. 3. Ordination from PCoA in three dimensions of D. speciosum individuals throughout the distribution range using vegetative and floral morphological characters. (a) Axis 1 v. 2. (b) Axis 2 v. 3. Character vectors (correlations $>0.7$ ) showing angles in ordination space are shown. See Table 2 for character codes. 


\section{Cluster analysis using vegetative or floral characters alone}

These analyses produced seven sub groups that were mixtures of plants from several different regions, similar to that produced by using all morphological characters.

\section{Principal coordinates analysis combining vegetative and floral morphological characters}

Rainforest plants north of Townsville partially separated from the main complex with minimal overlap. These plants form a group largely abutting the main complex in ordination space (Fig. 3). They partially separate on the basis of the presence of a collum, longer pedicels, and larger width at the top of the pseudobulbs. There are no absolute differences in characters of this group when compared to others. Presence of a collum also contributed to partial separation of var. hillii plants of rainforest in northern New South Wales and southern Queensland. Compared with all other D. speciosum, these plants had some of the longest pseudobulbs, which were wider at the top, with more internodes and longer leaves.

Plants of the dry country north of Townsville, typical habitat for var. pedunculatum, separate from var. curvicaule on the basis of longer peduncles. Longer peduncles are also found in some plants of var. boreale and not in all var. pedunculatum so the character is not diagnostic for var. pedunculatum. In the total analysis the other varieties all overlap without significant separation.

\section{Regional principal coordinates analysis}

The ordination of all 281 plants (Fig. 3) indicates a species complex. An analysis of regional subsets of plants was required to examine further for putative geographic varieties.

Regions 1 and 2: The northern rainforest group (var. boreale) has minimal overlap in ordination space with the southern rainforest group (var. curvicaule) of Region 2 (Fig. 4). There is considerable overlap between plants of var. pedunculatum in open forested dry country on and west of the divide, and var. boreale, and little overlap between var. pedunculatum and var. curvicaule.

Regions 3 and 4: The analysis indicates three groupings along the Tropic of Capricorn. The Carnarvon area group and Blackdown Tableland group abut one another with minimal overlap in the ordination space, and var. capricornicum of east Capricorn overlaps with the Blackdown Tableland group to some extent (Fig. 5). Variation in these regions is very extensive, especially at Blackdown Tableland, on the volcanic plugs near Rockhampton, and at Byfield and Shoalwater Bay. In the ordination space, plants from Mt Jim Crow, the type locality for var. capricornicum, lie at a considerable distance from those of other volcanic plugs.

Blackdown Tableland and Carnarvon Gorge plants are separated due to the higher character values in Carnarvon Gorge plants for forelobe length, flower length, dorsal sepal length, forelobe width, petal length and individual lateral sepal width. Plants on the plugs are separated from Blackdown Tableland and Carnarvon Gorge plants by lower values for pseudobulb length and leaf length. 
a

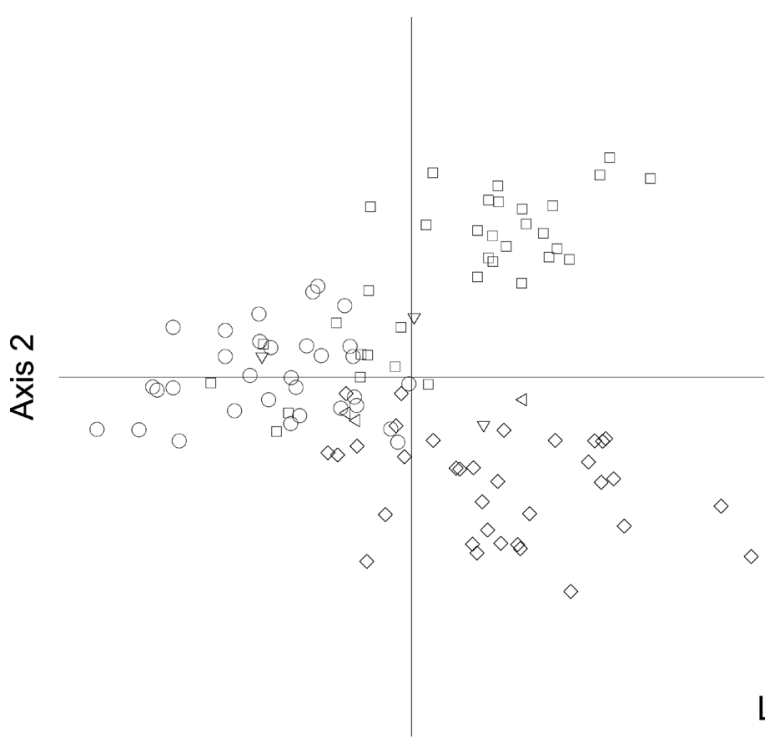

Axis 1

b

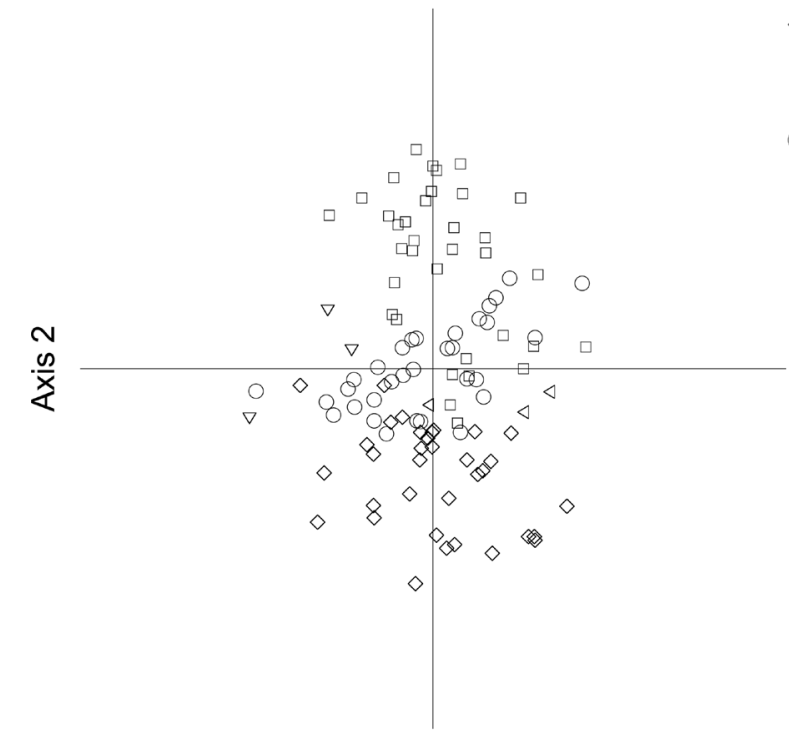

Axis 3

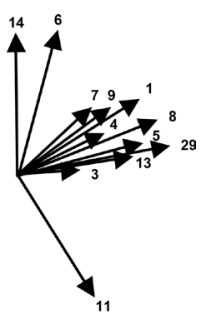

Locality

$\triangleleft$ Paluma

$\nabla$ Tinaroo

$\diamond$ Southern rainforest

$\square$ Northern rainforest

Dry open forest

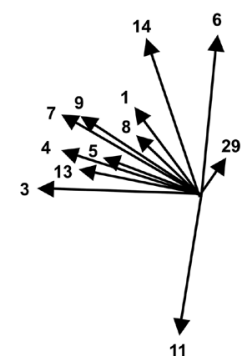

Fig. 4. Ordination from PCoA in three dimensions of $D$. speciosum individuals from north Queensland using vegetative and floral morphological characters. (a) Axis 1 v. 2. (b) Axis 2 v. 3. Character vectors (correlations $>0.7$ ) showing angles in ordination space are shown. See Table 2 for character codes. 
Regions 5 and 6: Ordination of Region 5 plants (var. grandiflorum) and plants along the Tropic of Capricorn (Fig. 6) indicate a small degree of overlap between Region 5 and plants of Blackdown Tableland and Carnarvon Gorge. Shorter plants from isolated populations of the southern part of Region 2 (Sarina, Clairview), and northern part of Region 5 (Mt Morgan area) (Fig. 6), overlap in ordination space with the three groups of Regions 3 and 4. There is no overlap between plants of Region 5 and east Capricorn. Ordination of Regions 5 and 6 indicated no significant sub groupings in each of these areas (Figs 7, 8). Intermediates are found at the junction between Regions 5 and 6, where the distribution of D. speciosum is continuous.

Regions 7 and 8: In the habitat of var. speciosum, there is a cohesive group with no significant sub groupings (Fig. 9).

\section{Two new taxa from central Queensland}

On the basis of field studies, regional ordination and cluster analysis, we consider that var. capricornicum Clemesha does not encompass the variation seen in west Capricorn, at Blackdown Tableland and the Carnarvon area, and recommend it be used only for plants from the volcanic plugs and forests of east Capricorn near Rockhampton, Yeppoon and Byfield.

Field observations and the numerical analyses are used to describe two new taxa. For all taxa, in the descriptions that follow, the dimensions used for flower vertical height and horizontal width refer to flowers pressed flat, as presentation dimensions have been shown to vary widely under different environmental conditions and at different times during the day (Burke 1998).

Dendrobium speciosum Sm. var. blackdownense P. B.Adams var. nov.

Plantae variabiles sed saepe urceolatae; axes breves vel mediocres (9-28 cm longi) e basi saepe divergentes; folia ovata vel subelliptica; racemi mediocres vel longi ex comparatione altitudinis plantae $(23-58 \mathrm{~cm}$ longi) pauciflori vel multiflori; flores subdistantes vel aggregati (14-113 per racemum), parvi vel mediocres $(3.5-5.4 \mathrm{~cm}$ alti) late aperientes; tepala albida vel ochroleuca.

Type: Queensland, Leichhardt District, Blackdown Tableland, P. B. Adams \& S.D. Lawson, 4 Sep1994 (holo: QRS; iso: BRI, MEL).

Plants very variable in size and shape, occasional plants showing a tendency to produce aerial roots; axes and leaves exhibiting purple pigmentation in parts exposed to direct light. Leaf bearing axes 9-28 cm long, $2.1-3.8 \mathrm{~cm}$ wide at mid point, round to oval in cross section, variably erect or curved, $1.9-4.6 \mathrm{~cm}$ wide at base, $1.5-3.2 \mathrm{~cm}$ wide at apex. Leaves terminal, 2-4, rigid, concave, 9-20 cm long, 4.3-7 cm wide, mainly ovate to sub-elliptic, broadly ovate on small plants, with a sheathing base, variably sub-elliptic or sub-oblong, concave, rigid, 1-2 mm thick. Racemes 1-3, 23-58 cm long; peduncle 8-15.5 cm long, 4-6 mm wide, with 1-4 medium sized bracts; rachis $15-42 \mathrm{~cm}$ long, 14-113-flowered: flower density varying from openly spaced to densely clustered, forming a brush. Pedicel including ovary $2.3-3.7 \mathrm{~cm}$ long. Flowers usually opening widely, variable in size and substance, vertical height $3.5-5.4 \mathrm{~cm}$, horizontal width $3.9-5.4 \mathrm{~cm}$, off white to deep gold, the labellum variously and diffusely marked with purple spots or short bars over forelobe and midlobe. Dorsal sepal 1.8-3 cm long, 

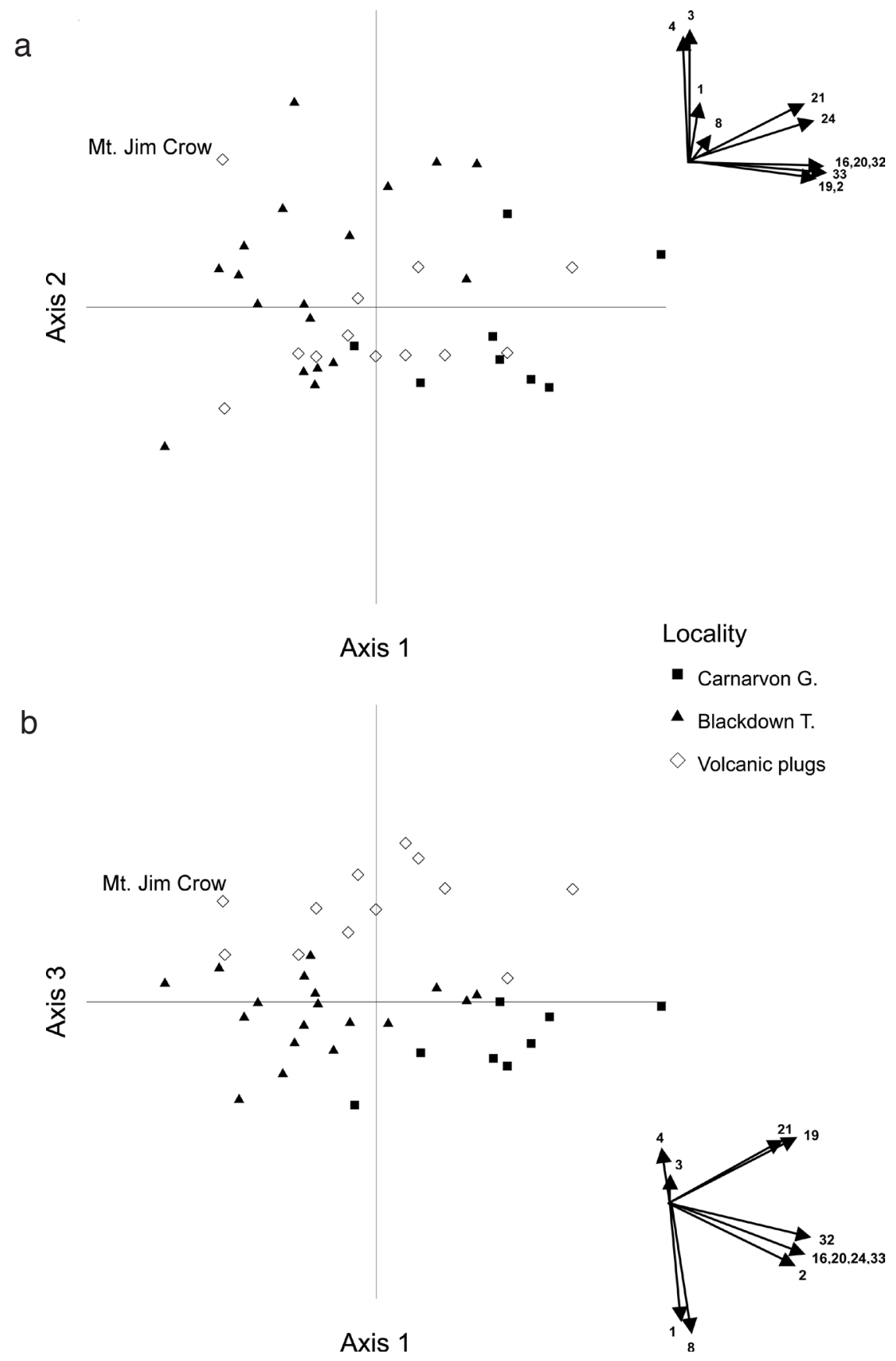

Fig. 5. Ordination from PCoA in three dimensions of D. speciosum individuals from central Queensland with vegetative and floral morphological characters. (a) Axis 1 v. 2. (b) Axis 1 v. 3. Character vectors (correlations $>0.8$ ) showing angles in ordination space are shown. See Table 2 for character codes. 
$0.5-0.8 \mathrm{~cm}$ wide at the base, tapering to an obtuse-rounded apex. Lateral sepals 1.6-2.4 cm long, 0.7-1 cm wide at base, falcate-oblong, obtuse at apex. Petals 1.8-2.7 $\mathrm{cm}$ long, 3-4 mm wide, slightly falcate, with an acute apex. Labellum $0.8-1.3 \mathrm{~cm}$ long, $0.9-1.2 \mathrm{~cm}$ wide; forelobe $0.5-0.7 \mathrm{~cm}$ long, $0.9-1.2 \mathrm{~cm}$ wide when flattened, incurved, subtriangular; midlobe shortly clawed, $0.3-0.6 \mathrm{~cm}$ long, $0.7-1.0 \mathrm{~cm}$ wide when flattened, presenting as a curved channel with a short acute apex; callus slightly raised, 2-ridged, yellow to orange. Column c. $5 \mathrm{~mm}$ long with a foot c. $6 \mathrm{~mm}$ long at right angles to it. Mentum bifid, rounded, c. $7 \mathrm{~mm}$ from ovary to apex.

Variation: the most variable in vegetative and floral form of all the described varieties, with flowers densely or openly spaced, flowers white to deep gold, and plant height and shape varying greatly over the wide range of habitats in this region.

Flowering time: August-September.

Distribution: from the northern limit of Blackdown Tableland southwards along the Expedition Range, southern limit not determined.

Etymology: the epithet refers to Blackdown Tableland.

Illustration: see Fig. 10.

Notes: the population is geographically separated from plants of the Great Dividing Range on the east coast and Carnarvon Gorge to the west, by flood plains that are unsuitable habitat for D. speciosum. Plants of D. speciosum var. blackdownense are usually lithophytic, urn or basket shaped, occasionally epiphytic in sclerophyll forests, dry rainforest and exposed rocky cliff faces, often forming dense populations with Drynaria (Bory) J.Sm. fern on huge boulders out of reach of fire. Larger plants may have a few aerial roots, which are not usually well developed. Some plants are extremely short and compact at maturity. Although very variable, they can usually be distinguished from var. carnarvonense, which tend to be more robust, with large flowers of very heavy substance. There is some overlap in floral and vegetative characters with plants of var. capricornicum, which can usually be distinguished by vegetative features of shorter axes and leaves, more upright plant shape, and an earlier flowering time (May-June).

Dendrobium speciosum Sm. var. carnarvonense P. B.Adams var. nov.

Planta robusta, plerumque urceolata vel crateriforma; axes breves vel mediocres (15-33 cm longi) e basi divergentes, basi lati, apicem versus contracti; racemi breves vel mediocres (21-47 cm longi); flores $25-87$ per racemum, subdistantes, grandes (5.1-6.6 cm alti), cupulati; segmenta lata crassiuscula; lobus frontalis $1-1.4 \mathrm{~cm}$ latus et c. $0.7 \mathrm{~cm}$ longus; tepala cremea vel aurea.

Type: Queensland Leichhardt District. Carnarvon Gorge, P.B. Adams \& S.D. Lawson, 11 Sep 1994 (holo: QRS; iso: BRI, MEL).

Plants robust, urn or basked shaped, with wide based, tapering pseudobulbs. Occasional plants produce aerial roots; axes and leaves may exhibit purple pigment in areas exposed to direct light. Leaf bearing axes $15-33 \mathrm{~cm}$ long, $2.1-3.1 \mathrm{~cm}$ wide at mid point, round to oval in cross section, variably curved, $2-5.2 \mathrm{~cm}$ wide at base, $1.3-3.2 \mathrm{~cm}$ wide at apex. Leaves terminal, 2-3, rigid to very rigid, concave, sub-elliptic to oblanceolate or ovate, with a sheathing base, $14.8-24 \mathrm{~cm}$ long, 4.6-7.4 cm wide, concave, rigid, 1.2-2.0 mm thick. Racemes stout, 1-2, 21-47 cm long; peduncle 7-14.8 cm long, 
a
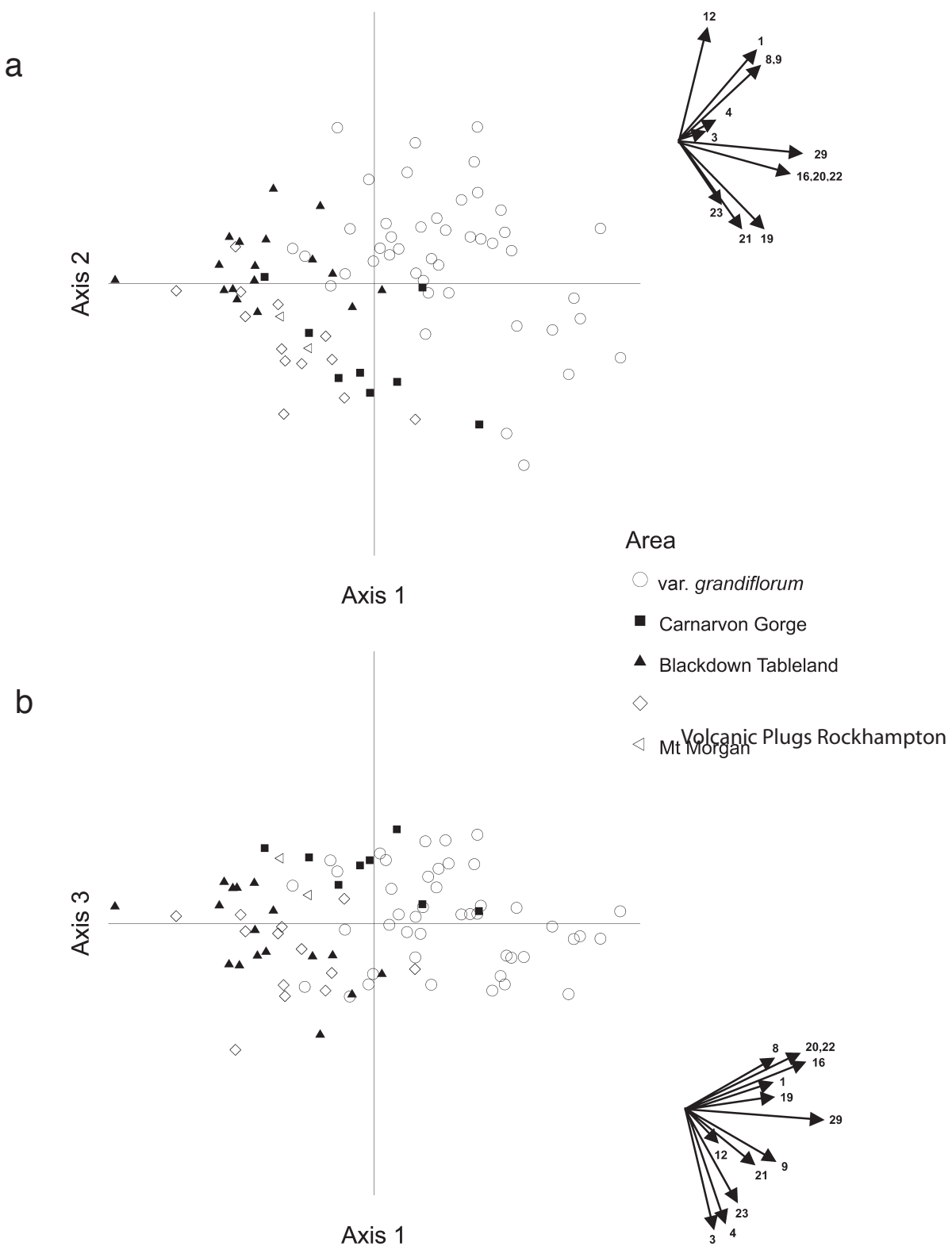

Fig. 6. Ordination from PCoA in three dimensions of D. speciosum var. grandiflorum individuals and individuals from along the Tropic of Capricorn using vegetative and floral morphological characters. (a) Axis 1 v. 2. (b) Axis 1 v. 3. Character vectors (correlations $>0.8$ ) showing angles in ordination space are shown. See Table 2 for character codes. 
4.5-7 mm wide, with 1-4 medium bracts; rachis 14.5-31.5 cm long, 25-87-flowered: flowers well spaced. Pedicel including ovary $2.7-4.5 \mathrm{~cm}$ long. Flowers usually cupped and of heavy substance, medium to large flowered, vertical height $5.1-6.6 \mathrm{~cm}$, horizontal width $5.5-6.3 \mathrm{~cm}$, cream to gold, the labellum variously purple barred or spotted over forelobe and midlobe, markings diffuse and variable. Dorsal sepal $2.8-3.9 \mathrm{~cm}$ long, $0.5-0.8 \mathrm{~cm}$ wide at base, tapering to an obtuse-rounded apex. Lateral sepals $2.1-2.5 \mathrm{~cm}$ long, 0.8-1.1 cm wide at base, falcate-oblong, obtuse at apex. Petals $2.4-3.4 \mathrm{~cm}$ long, 2.8-4 mm wide, almost linear with an acute apex. Labellum $1.1-1.4 \mathrm{~cm}$ long, $1-1.3 \mathrm{~cm}$ wide when flattened; forelobe $0.7-0.8 \mathrm{~cm}$ long, $1.1-1.4 \mathrm{~cm}$ wide, incurved, subtriangular; midlobe shortly clawed, $0.4-0.6 \mathrm{~cm}$ long, $0.9-1.0 \mathrm{~cm}$ wide when flattened, presenting as a curved channel with a short acute apex; callus raised, 2-ridged, low profiled, yellow to orange. Column c. $5 \mathrm{~mm}$ long with a foot c. $6 \mathrm{~mm}$ long at right angles to it. Mentum bifid, rounded, c. $7 \mathrm{~mm}$ long from ovary to apex.

Flowering time: August-September.

Distribution: gorges of the Carnarvon region; geographically separate from other varieties.

Etymology: the epithet refers to the Carnarvon Region.

Illustration: see Fig. 11.

Notes: plants of D. speciosum var. carnarvonense are usually lithophytic, in protected sites along escarpments and rocky creeks. They are usually distinguishable from var. blackdownense by more robust, tapering pseudobulbs and large flowers of heavier substance. They are larger and more robust plants compared to var. capricornicum, and their flowers, which open later, usually have wider segments. They most closely resemble var. speciosum in plant form, flower shape and substance, as also indicated in numerical analyses. Like var. capricornicum and var. blackdownense, new growths show a strong development of purple anthocyanin pigment, which is not usually evident in the mature leaves.

\section{Descriptions of other varieties}

These are based on measurements of 453 plants combined with field observations. Occasional plants may be encountered with measurements outside of the ranges of values presented here. Details of the type collection for recently described var. boreale and neotypified var. curvicaule are provided.

Dendrobium speciosum Sm. var. speciosum, Exotic Bot. 1:17, t.10 (1804)

Plants variable, basket or urn shaped, with curved axes or more erect if axes less curved. Usually lacking aerial roots, but occasional plants produce them; axes and leaves exhibiting purple pigmentation in parts exposed to direct light. Leaf bearing axes usually wide based and tapering towards the apex, $13-51 \mathrm{~cm}$ long, $2.1-4.5 \mathrm{~cm}$ wide at mid point, round to oval in cross section, variably erect or curved, $2.8-6.0 \mathrm{~cm}$ wide at base, $1.4-3.2 \mathrm{~cm}$ wide at apex. Leaves terminal, $2-5$, rigid to very rigid, concave, sub-elliptic to ovate, occasionally oblanceolate, relatively broad at the sheathing base, 9-20 cm long and 4-12 cm wide, 1-2 mm thick. Racemes 1-4, 14.5-57 cm long; peduncle 5-16 cm long, 4.6-9.5 mm wide, with 1-4 medium sized bracts; rachis 


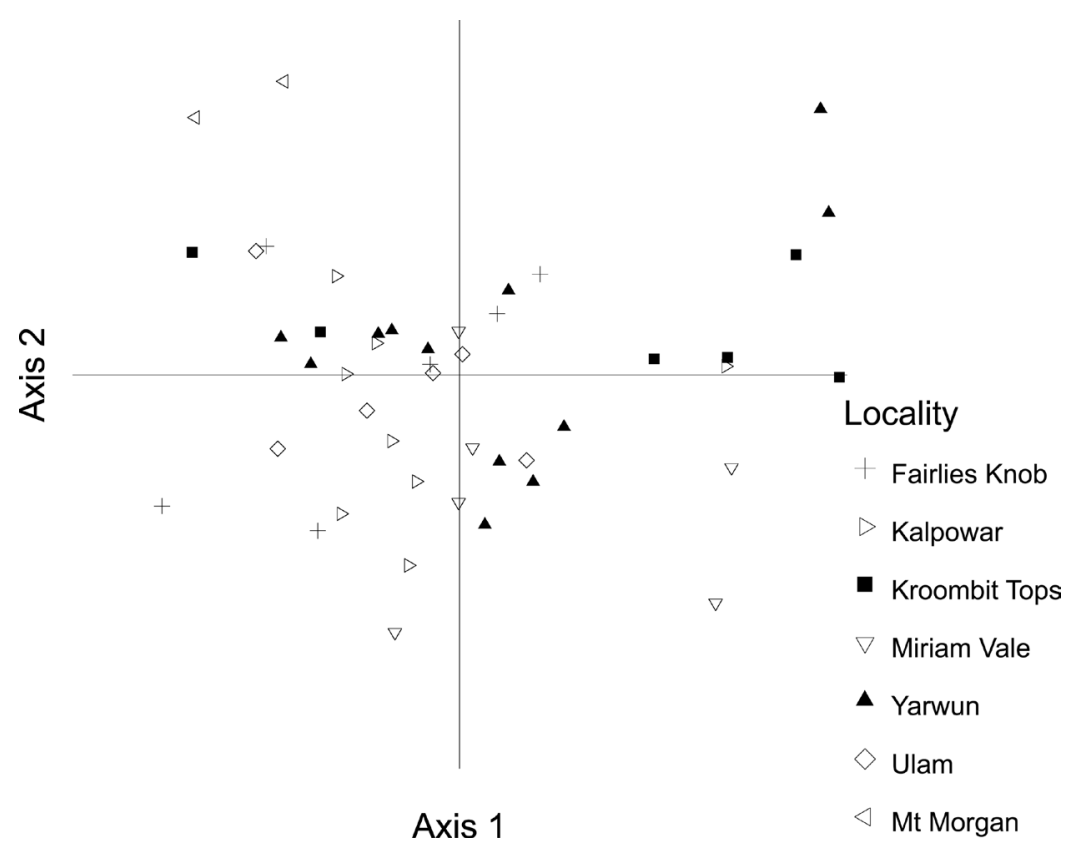

Fig. 7. Ordination from PCoA of D. speciosum var. grandiflorum individuals using vegetative and floral morphological characters. Axis 1 v. 2.

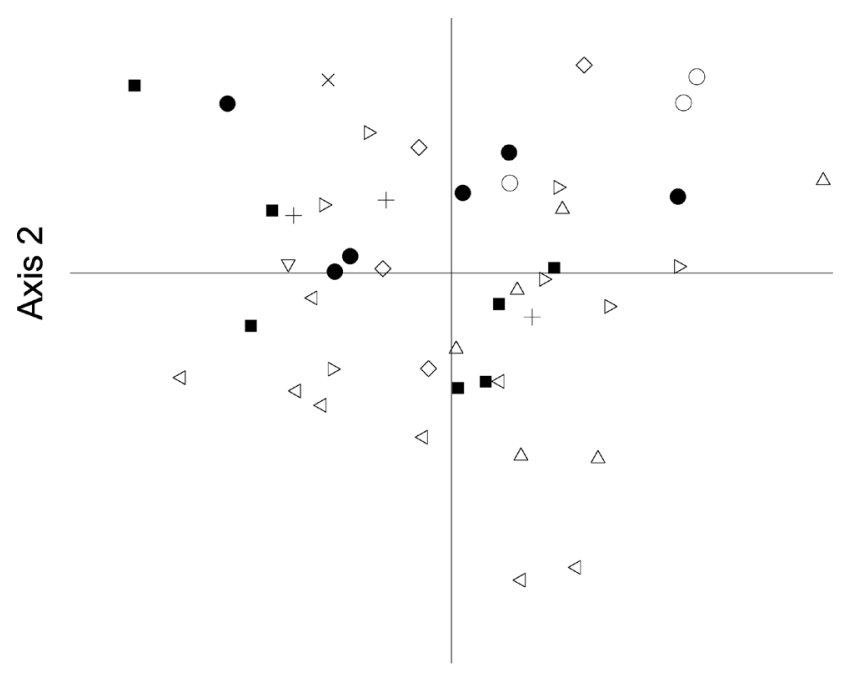

Axis 1
Locality

- Telegerry

- Gloucester

$\times$ Bennys Tops

+ Yarras

$\triangleright$ Hastings River

$\triangleleft$ Kempsey

$\nabla$ Urunga

$\triangle$ Dorrigo

$\diamond$ Tenterfield

Rocky River

Fig. 8. Ordination from PCoA of D. speciosum var. hillii individuals using vegetative and floral morphological characters. Axis 1 v. 2. 
15-41 cm long, 18-115-flowered: flower density varying from openly spaced to fairly densely clustered. Pedicel including ovary $2.7-5.6 \mathrm{~cm}$ long. Flowers usually opening moderately or widely, variable in substance, vertical height $4.2-8 \mathrm{~cm}$, horizontal width $4.3-7.8 \mathrm{~cm}$, off white to deep gold, labellum variously and diffusely marked with purple spots or short bars over forelobe and midlobe. Dorsal sepal $2.5-4.6 \mathrm{~cm}$ long, $0.4-1.0 \mathrm{~cm}$ wide at the base, tapering to an obtuse-rounded apex. Lateral sepals $1.8-3.9 \mathrm{~cm}$ long, $0.7-1.2 \mathrm{~cm}$ wide at base, falcate-oblong, obtuse at apex. Petals $2.2-4.1 \mathrm{~cm}$ long, $2-5 \mathrm{~mm}$ wide, slightly falcate, with an acute apex. Labellum $1.1-1.7 \mathrm{~cm}$ long, $0.8-1.5 \mathrm{~cm}$ wide when flattened; forelobe $0.6-0.9 \mathrm{~cm}$ long, $0.8-1.5 \mathrm{~cm}$ wide, incurved, subtriangular; midlobe shortly clawed, $0.3-0.8 \mathrm{~cm}$ long, $0.6-1.2 \mathrm{~cm}$ wide when flattened, presenting as a curved channel with a short acute apex; callus slightly raised, 2-ridged, yellow to orange. Column 4-5 mm long with a foot 5-6 mm long at right angles to it. Mentum bifid, rounded, 6-7 $\mathrm{mm}$ from ovary to apex.

Flowering time: August-October, or November in eastern Victoria.

Distribution: from Genoa, eastern Victoria (formerly at Cann River, but reportedly extinct there now), north to Bulahdelah, Barrington Tops, New South Wales. Inland, west $200 \mathrm{~km}$ to Munghorn Gap near Mudgee, New South Wales.

Notes: large robust plants which may form dense colonies covering whole rock faces on the eastern escarpments of the Great Dividing Range. Occur from sea level to the tops of ranges in open and closed sclerophyll forest and rainforest. In rainforest it is also lithophytic and less frequently an epiphyte, occasionally with aerial roots. Pseudobulbs wide at base, often curved and tapering towards the apex. Flowers relatively large and well spaced, including superior horticultural forms. Larger flowered forms occur in the

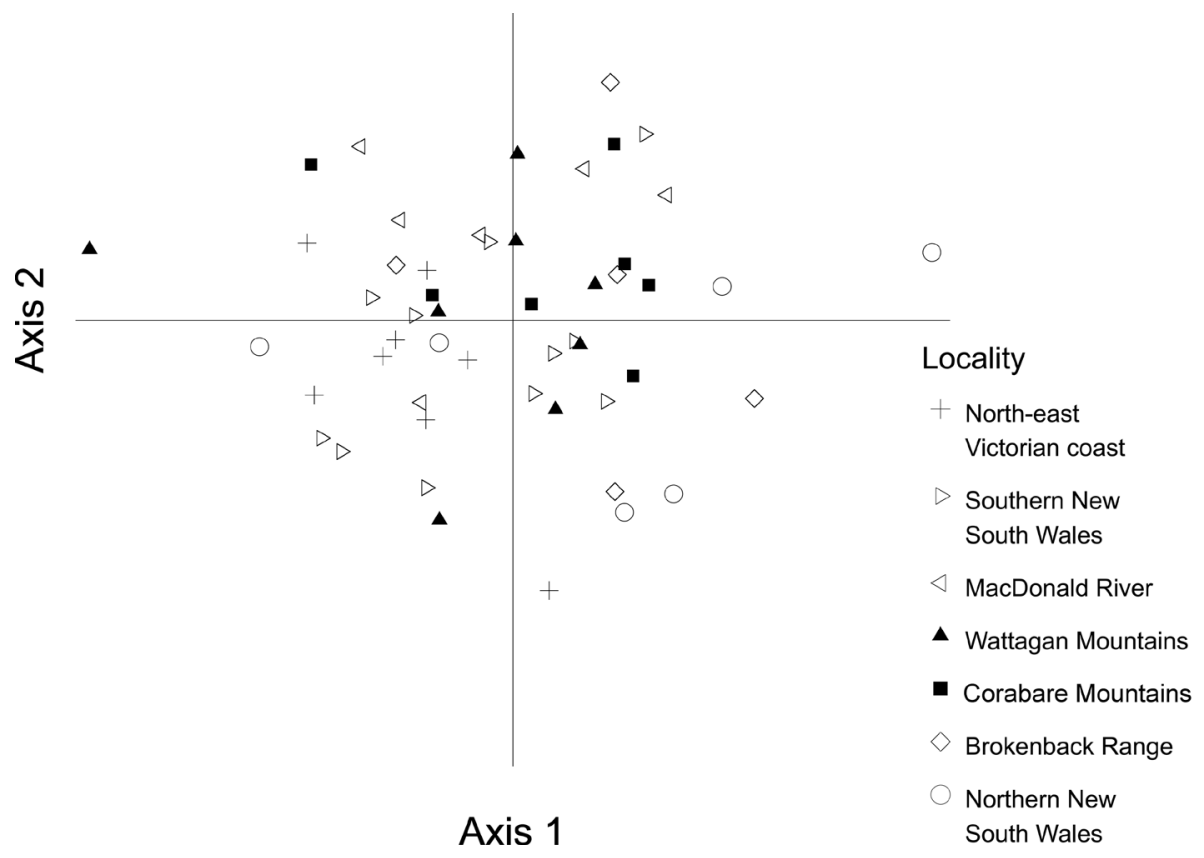

Fig. 9. Ordination from PCoA of D. speciosum var. speciosum individuals using vegetative and floral morphological characters. Axis 1 v. 2. 

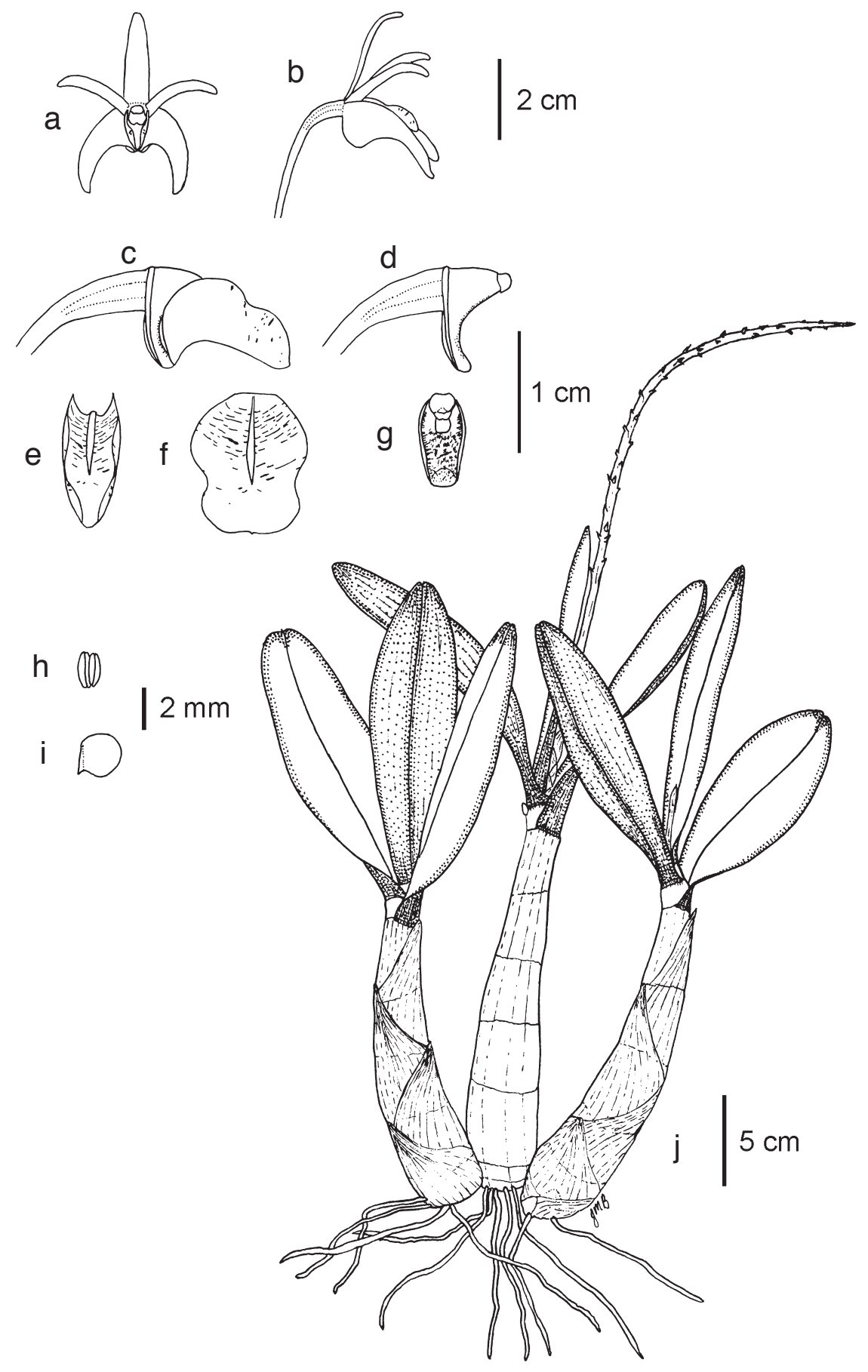

Fig. 10. Dendrobium speciosum var. blackdownense: (a) whole flower, front view; (b) whole flower, side view; (c) ovary, column and labellum, side view; (d) ovary and column, side view; (e) labellum, top view; (f) flattened labellum, top view; (g) column, front view; (h) pollinium; (i) anther, side view; (j) plant habit. 
northern half of the range, from pure white to golden yellow. The variety is variable in size, plant shape and floral dimensions, but less so than most of the more northerly varieties, and intergrades with var. hillii primarily north of the Hunter River, New South Wales.

Dendrobium speciosum Sm. var. hillii Mast., Gard. Chron. (new ser.) 7: 112, f. 18 (1877)

Plants variable, tall and upright in habit, commonly producing aerial roots, especially prominent and erect in large rainforest plants. Leaf bearing axes 16-68 cm long, $1.8-5.2 \mathrm{~cm}$ wide at mid point, oval in cross section, may be considerably flattened, variably erect or gently curved, $1.4-4.4 \mathrm{~cm}$ wide at base, $1.5-4.2 \mathrm{~cm}$ wide at apex. Leaves terminal, $2-5$, often very large, rigid, concave, sub-elliptic to oblanceolate, occasionally ovate, relatively broad at the sheathing base, $13-28 \mathrm{~cm}$ long, $6-12 \mathrm{~cm}$ wide, $1-2 \mathrm{~mm}$ thick. Racemes 1-4, 26-65 cm long; peduncle 6-13.6 cm long, 4-9.5 mm wide, with 1-4 medium sized bracts; rachis 20-51 cm long, 44-221-flowered: flower density varying from openly spaced to densely clustered. Pedicel including ovary $2.3-4.6 \mathrm{~cm}$ long. Flowers small to medium, opening variably, may remain cupped, usually light in substance, vertical height $3.4-5.2 \mathrm{~cm}$, horizontal width $2.9-5.3 \mathrm{~cm}$, usually off white to pale yellow, the labellum variously and diffusely marked with purple spots or short bars over forelobe and midlobe. Dorsal sepal $1.9-3.7 \mathrm{~cm}$ long, $0.4-0.6 \mathrm{~cm}$ wide at the base, tapering to an obtuse-rounded apex. Lateral sepals $1.4-2.7 \mathrm{~cm}$ long, $0.6-0.9 \mathrm{~cm}$ wide at base, falcate-oblong, obtuse at apex. Petals $1.8-3.2 \mathrm{~cm}$ long, $2-3 \mathrm{~mm}$ wide, slightly falcate, with an acute apex. Labellum $0.8-1.3 \mathrm{~cm}$ long, $0.7-1.0 \mathrm{~cm}$ wide when flattened; forelobe $0.5-0.8 \mathrm{~cm}$ long, $0.7-1.0 \mathrm{~cm}$ wide, incurved, subtriangular; midlobe shortly clawed, $0.3-0.5 \mathrm{~cm}$ long, $0.5-0.8 \mathrm{~cm}$ wide when flattened, presenting as a curved channel with a short acute apex; callus slightly raised, 2-ridged, yellow to orange. Column 4-5 $\mathrm{mm}$ long with a foot 4-6 $\mathrm{mm}$ long at right angles to it. Mentum bifid, rounded, 5-6 $\mathrm{mm}$ from ovary to apex.

Flowering time: August-October.

Distribution: occurs, or formerly occurred, just south of the Hawkesbury River in central eastern New South Wales, to Mt Mee-Crows Nest in southern Queensland, where it begins to intergrade with var. grandiflorum.

Notes: in optimal moist rainforest habitat these plants are very large epiphytes with pseudobulbs more than a metre in height, and forming masses in the canopy several metres in diameter. They are much more abundant and larger in upland forest. In more exposed and drier habitat, rainforest or open forests, they are smaller, and occur as lithophytes or epiphytes. Recognizable by erect, relatively slender, virtually nontapering pseudobulbs, relatively large leaves and long racemes crowded with many small, white to cream, or occasionally pale yellow flowers. Aerial roots are less common in more exposed sites. At the western limit and at the intergrade with D. speciosum, plants may be squat, atypical, and with widely spaced large flowers which are difficult to identify as this variety. 

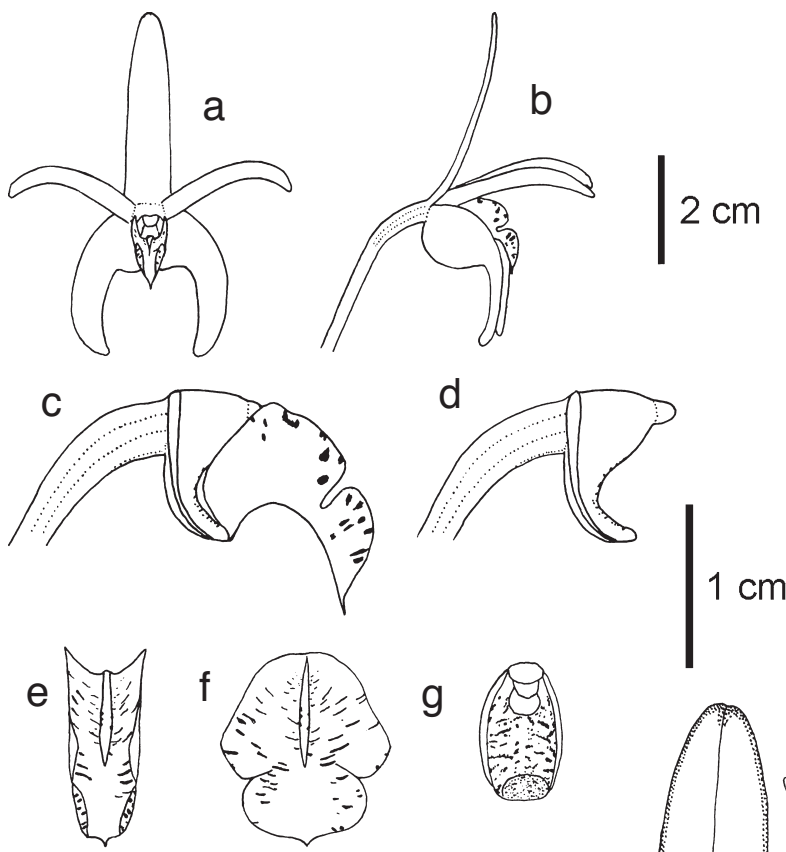

9

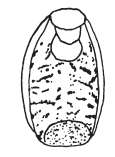

$\mathrm{h}$
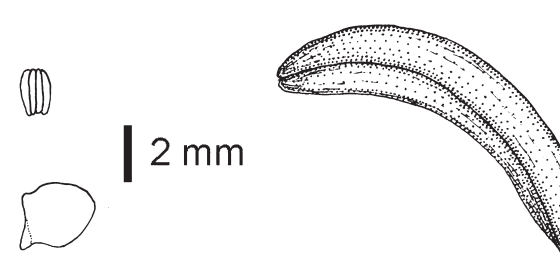

$5 \mathrm{~cm}$

Fig. 11. Dendrobium speciosum var. carnarvonense: (a) whole flower, front view; (b) whole flower, side view; (c) ovary, column and labellum, side view; (d) ovary and column, side view; (e) labellum, top view; (f) flattened labellum, top view; (g) column, front view; (h) pollinium; (i) anther, side view; (j) plant habit. 
Dendrobium speciosum Sm. var. grandiflorum F.M.Bailey, Bot. Bull., Dept Agric 14:12 (1896)

Plants variable, often epiphytic, with very large rainforest forms, commonly with well developed aerial roots. Leaf bearing axes $17-95 \mathrm{~cm}$ long, $2.6-5.5 \mathrm{~cm}$ wide at mid point, oval or flattened oval in cross section, variably erect or curved, $1.8-3.3 \mathrm{~cm}$ wide at base, 1.5-3.2 cm wide at apex. Leaves terminal, 2-6, often large, rigid, concave, sub-elliptic to oblanceolate, with a short sheathing base, $12-37 \mathrm{~cm}$ long, 5-10 $\mathrm{cm}$ wide, $1-2 \mathrm{~mm}$ thick. Racemes 1-4, short to very long, 25-70 cm long; peduncle 9-16 cm long, 4.5$9.5 \mathrm{~mm}$ wide, with 1-5 medium sized bracts; rachis $16-54 \mathrm{~cm}$ long, 41-123-flowered: flower density varying from openly spaced to densely clustered, small to large sized including some of the largest in the species. Pedicel including ovary $3.2-5.7 \mathrm{~cm}$ long. Flowers very variable in substance, usually opening widely, pale yellow to deep gold, occasionally bicolour with a cream-white centre, and rarely pure white, vertical height $4.7-8.1 \mathrm{~cm}$, horizontal width $4.8-8.0 \mathrm{~cm}$, the labellum variously and diffusely marked with purple spots or short bars over forelobe and midlobe. Dorsal sepal tends to be much larger in relation to other segments, $2.7-4.7 \mathrm{~cm}$ long, $0.6-0.9 \mathrm{~cm}$ wide at base, tapering to an obtuse-rounded apex. Lateral sepals $2.3-4.5 \mathrm{~cm}$ long, $0.8-1.1 \mathrm{~cm}$ wide at base, falcate-oblong, obtuse at apex. Petals $2.4-4.2 \mathrm{~cm}$ long, 3-5 mm wide, slightly falcate, with an acute apex. Labellum 1-1.6 cm long, 1.7-2.5 cm wide when flattened; forelobe $0.6-0.9 \mathrm{~cm}$ long, $1-1.4 \mathrm{~cm}$ wide, incurved, subtriangular; midlobe shortly clawed, $0.4-0.7 \mathrm{~cm}$ long, $0.7-1.1 \mathrm{~cm}$ wide when flattened, presenting as a curved channel with a short acute apex; callus slightly raised, 2-ridged, yellow to orange. Column 5-6 mm long with a foot 5-7 $\mathrm{mm}$ long at right angles to it. Mentum bifid, rounded, 6-8 $\mathrm{mm}$ from ovary to apex.

Flowering time: August - October.

Distribution: including the interface with var. hillii, it occurs from Mt Mee-Crow's Nest, to the Mt Morgan area.

Notes: found in suitable rainforest habitat where it forms dense populations in the canopy on many rainforest trees, and hoop pines (Araucaria cunninghamii Aiton ex D. Don) and along rocky creeks and escarpments. Pseudobulbs may be almost one metre long in the rainforest, and similar to, but often thicker than those seen in var. hillii, with very large leaves in shady habitat. In more exposed situations as epiphytes or lithophytes, plants may be only $20 \mathrm{~cm}$ high, with short, straight or curved pseudobulbs. In the south of the range there is a gradual merging with var. hilli, where many plants are short, smaller, or with pale yellow flowers. Deep yellow colour and large flowers with prominent dorsal sepals help to distinguish only some plants of the variety. Unusual coloured forms of yellow flowers with white centres are reported between Kroombit Tops and Miriam Vale.

Dendrobium speciosum Sm. var. capricornicum Clemesha, Orchadian 7: 103 (1982)

Plants variable, relatively short and compact, small to medium sized, usually upright in shape and lithophytic, without aerial roots; axes and leaves exhibiting purple pigmentation in parts exposed to direct light. Leaf bearing axes usually cylindrical, 7-19 cm long, 2-3.8 cm wide at mid point, round to oval in cross section, variably erect or curved, 2-3.9 $\mathrm{cm}$ wide at base, $1.6-2.5 \mathrm{~cm}$ wide at apex. Leaves terminal, 2-5, 


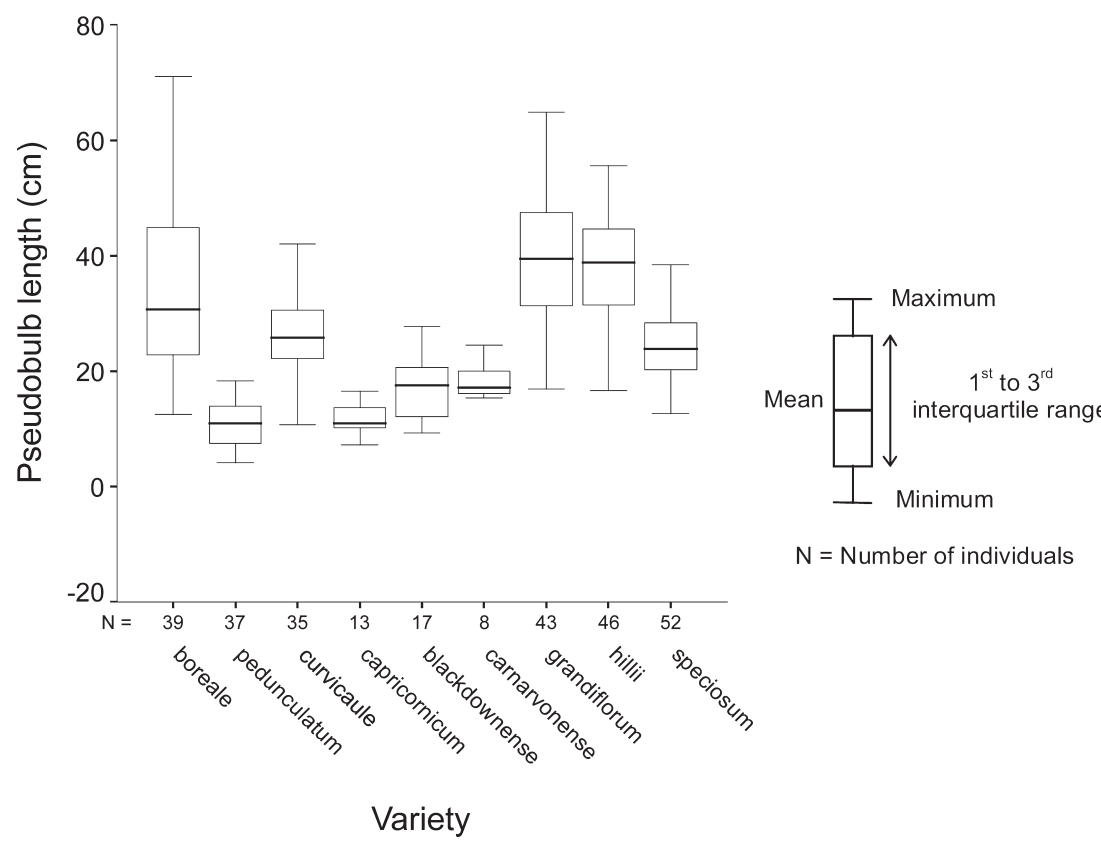

Fig. 12. Variation in pseudobulb length of Dendrobium speciosum varieties. $\mathrm{N}=$ number of individuals measured.

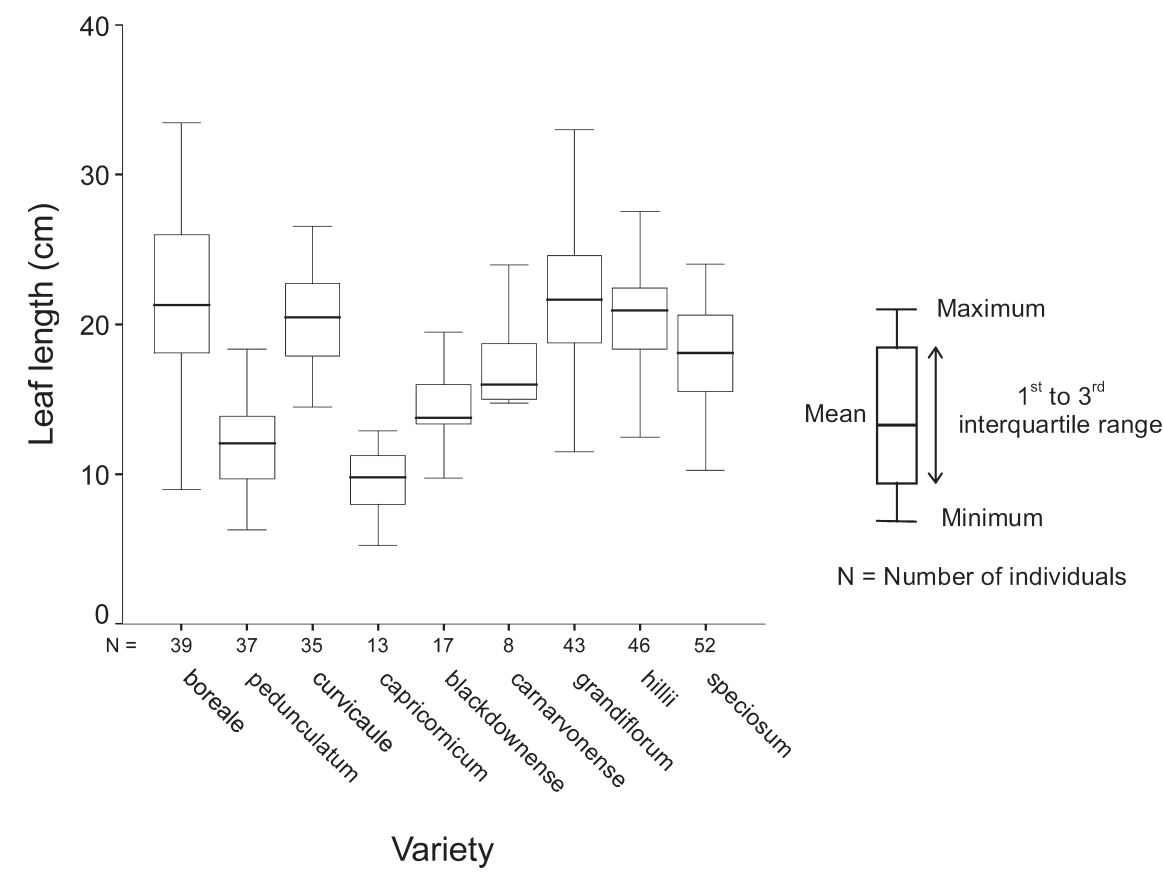

Fig. 13. Variation in leaf length of Dendrobium speciosum varieties. $\mathrm{N}=$ number of individuals measured. 
very rigid and coriaceous, often channelled, sub erect, ovate to oblanceolate, with a short sheathing base, 5-16 cm long, 4.5-6 cm wide, 1-3 mm thick. Racemes arching or erect, 1-2, 17-49 cm long; peduncle short to long, 9-22 cm long, 5-7 mm wide, with 1-3 medium sized bracts; rachis 8-27 cm long, 11-68-flowered; flower density varying from openly spaced to clustered. Pedicel including ovary $2.7-4.4 \mathrm{~cm}$ long. Flowers usually opening widely, very variable in substance, vertical height $3.4-5.9 \mathrm{~cm}$, horizontal width 3.9-5.6 cm, off white to deep gold, the labellum variously and diffusely marked with purple spots or short bars over forelobe and midlobe. Dorsal sepal $2.1-3.4 \mathrm{~cm}$ long, $0.5-0.8 \mathrm{~cm}$ wide at the base, tapering to an obtuse-rounded apex. Lateral sepals $1.6-2.9 \mathrm{~cm}$ long, $0.7-1.1 \mathrm{~cm}$ wide at base, falcate-oblong, obtuse at apex. Petals 1.9-3.0 cm long, 3-5 mm wide, slightly falcate, with an acute apex. Labellum $1-1.6 \mathrm{~cm}$ long, $1-1.2 \mathrm{~cm}$ wide when flattened; forelobe $0.6-0.9 \mathrm{~cm}$ long, $1-1.2 \mathrm{~cm}$ wide, incurved, subtriangular; midlobe shortly clawed, $0.4-0.7 \mathrm{~cm}$ long, $0.8-1.1 \mathrm{~cm}$ wide when flattened, presenting as a curved channel with a short acute apex; callus slightly raised, 2-ridged, yellow to orange. Column 4-5 mm long with a foot 5-6 mm long at right angles to it. Mentum bifid, rounded, 6-7 $\mathrm{mm}$ from ovary to apex.

Flowering time: May-August.

Distribution: Mt Morgan area to Byfield, and west to Berserker Range.

Notes: in east Capricorn, localised colonies with short and very coriaceous leaves are restricted to suitable habitat on volcanic plugs, and in forest and creek side locations at Byfield. On volcanic plugs, plants are exposed to full sun, and only their leaves may be evident between rock crevices. The bulk of the pseudobulbs are protected between layers of stone. In the northern part of the range occasional colonies occur with a wide variety of plant form, and well spaced yellow to gold flowers.

Dendrobium speciosum Sm. var. curvicaule F.M.Bailey, Bot. Bull., Dept Agric. 14:12 (1896)

Neotype (Adams et al. 2006a): Queensland. Kennedy North District: Cathu State Forest, P.B. Adams \& S.D. Lawson, 27 Jun 1993 (holo: QRS; isoneo: BRI, MEL).

Brief Neotype Diagnosis: Leaf-bearing axes short to medium (10.7-52 cm long), collum usually inconspicuous, peduncle short $(7.5-16 \mathrm{~cm}$ long), flowers moderately spaced to crowded, off white to bright yellow, tepals variably long, lateral sepals broad (0.8-1.2 $\mathrm{cm}$ wide), variably incurving.

Plants very variable in shape and size, aerial roots prominent in occasional plants. Leaf bearing axes curved, fusiform or linear, 10.7-52 cm long, 1.7-5.1 cm wide at midpoint, with an indistinct or absent collum at base, if collum present then widening distally over only $1-2 \mathrm{~cm}$, axis at base $1.3-4.0 \mathrm{~cm}$ wide, round to oval in cross section. Apex of axes usually narrowing to $1.4-3.4 \mathrm{~cm}$ wide, variably sharply edged only in the distal few centimetres. Leaves terminal, 2-4, 15-26.6 cm long, 4-9.2 cm wide, leaf shape variable, sub-elliptic to oblanceolate with a short sheathing base, concave, rigid, 1-2.7 mm thick, thinner, larger and more flexible leaves in dense shade, smaller and thicker when exposed to sun. Racemes 1-3, 20-65 cm long, peduncle 7.5-16 cm long, 3.7-7.9 mm wide, shorter than the rachis with prominent bracts; rachis 12.5$45.5 \mathrm{~cm}$ long, bearing 20-135 flowers, open or very closely spaced and overlapping, pedicel including ovary medium to very long, $2.2-5.2 \mathrm{~cm}$ long. Flowers small to 


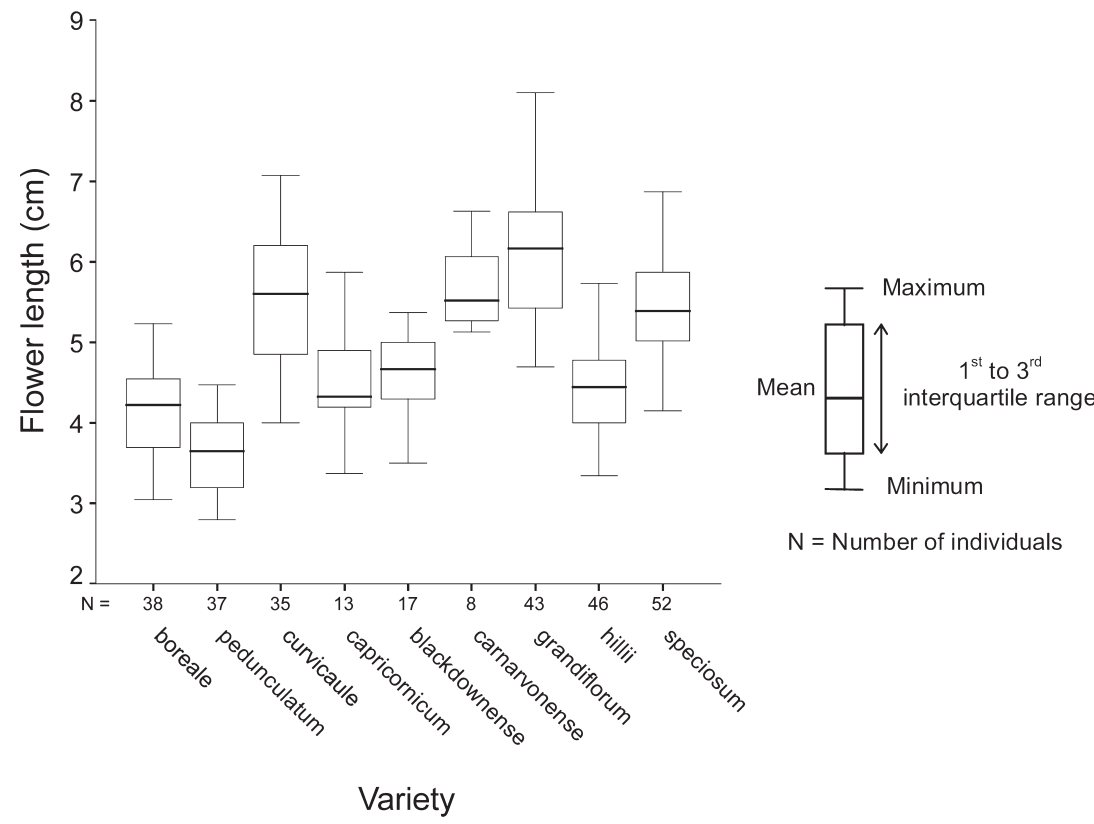

Fig. 14. Variation in flower length of Dendrobium speciosum varieties. $\mathrm{N}=$ number of individuals measured.

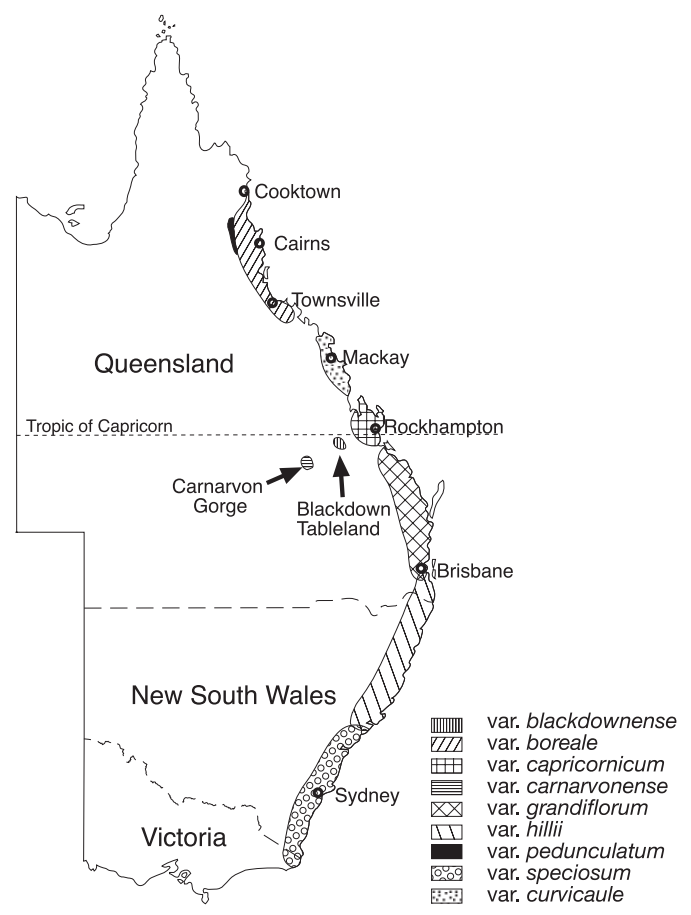

Fig. 15. Distribution of taxa of Dendrobium speciosum Smith. 
large, usually opening widely but sometimes cupped, $4-7.1 \mathrm{~cm}$ long vertically, 4.1-7 cm wide horizontally, off white to deep yellow segments with heavy substance, labellum white to cream, variously marked with purple spots or bars on forelobe and midlobe. Dorsal sepal $2.2-4.1 \mathrm{~cm}$ long, $0.6-1.0 \mathrm{~cm}$ wide, tapering from base to an obtuse-rounded apex. Lateral sepals $1.4-2.5 \mathrm{~cm}$ long, $0.8-1.2 \mathrm{~cm}$ wide, falcatooblong and obtuse at apex. Petals relatively long $2.1-3.6 \mathrm{~cm}$ long, $3-5 \mathrm{~mm}$ wide, almost linear and ending acutely. Labellum $0.9-1.5 \mathrm{~cm}$ long, $1-1.3 \mathrm{~cm}$ wide, forelobe $0.6-0.9 \mathrm{~cm}$ long, $1-1.3 \mathrm{~cm}$ wide when flattened, incurved and subtriangular, midlobe on a short claw, midlobe $0.3-0.6 \mathrm{~cm}$ long, $0.7-1.6 \mathrm{~cm}$ wide when flattened, presenting as a curved channel with short acute apex. Column c. $5 \mathrm{~mm}$ long with a foot 5-6 mm long at right angles to it, mentum bifid, rounded, $6-7 \mathrm{~mm}$ from ovary to apex. Callus raised, 2-ridged, low profiled, orange coloured.

Distribution: Mt Dryander north east of Proserpine, to St Lawrence, and the Whitsunday Islands.

Flowering time: August-September.

Notes: previously more broadly circumscribed to include plants treated here as var. boreale (Adams et al. 2006a). Predominantly a rainforest epiphyte from sea level to 1200 metres, on large trees such as Tulip Oak (Argyrodendron actinophyllum (Bailey) Edlin) and Red Cedar (Toona australis (F. Muell.) Harms), often as very large plants over two metres in diameter, usually high in the canopy, where populations may be very dense. Smaller, shorter plants are found in more exposed open forest as epiphytes or lithophytes, and along watercourses on Casuarina L. ex Adans. Short diminutive plants are found at sea level on the Whitsunday Coast. They have been discussed and illustrated by Dockrill (1992, pp. 462-463), who considered it a possible sub coastal variety. These forms represent atypical ecotypes comparable to those that are often seen at the eastern and western habitat limits for most other varieties (see also var. hillii). South of Sarina, colonies are isolated, and form an intergrade with var. capricornicum along dry watercourses. Flowers are usually cream, but may be deep yellow or gold. They may be small or large, with broad segments, and represent some of the finest horticultural forms of the species.

Dendrobium speciosum Sm. var. boreale P.B.Adams, J.M.Burke \& S.D.Lawson [ms.] Aust. Syst. Bot. (2006a)

Type: Queensland. Cook District: Windsor Tableland, B. Gray, P.B. Adams, J.M. Burke \& S.D. Lawson, 3 Aug 2004, (holo: QRS; iso: BRI, MEL).

Brief Diagnosis: Leaf-bearing axes short to long $(12.6-71 \mathrm{~cm})$, rarely curved; collum usually prominent; peduncle moderately long $(8-29 \mathrm{~cm})$ but not longer than rachis; flowers well spaced; tepals off white to pale yellow, broad in relation to length; lateral sepals moderately broad $(0.7-1.0 \mathrm{~cm})$ with little incurving.

Plants very variable in shape and habit, occasionally producing aerial roots. Leafbearing axes $12.6-71.0 \mathrm{~cm}$ long, $1.4-4.6 \mathrm{~cm}$ wide at mid point, with little tapering or shorter and fusiform, usually with a prominent collum at base $1.3-4.4 \mathrm{~cm}$ long, axis at base 1.3-2.7 cm wide, oval or flattened in cross section, erect or curved or gently angled once or twice in distal half, sharply edged over distal half (especially notable in axes of taller plants 1-2 years old), tapering or broadening towards apex 

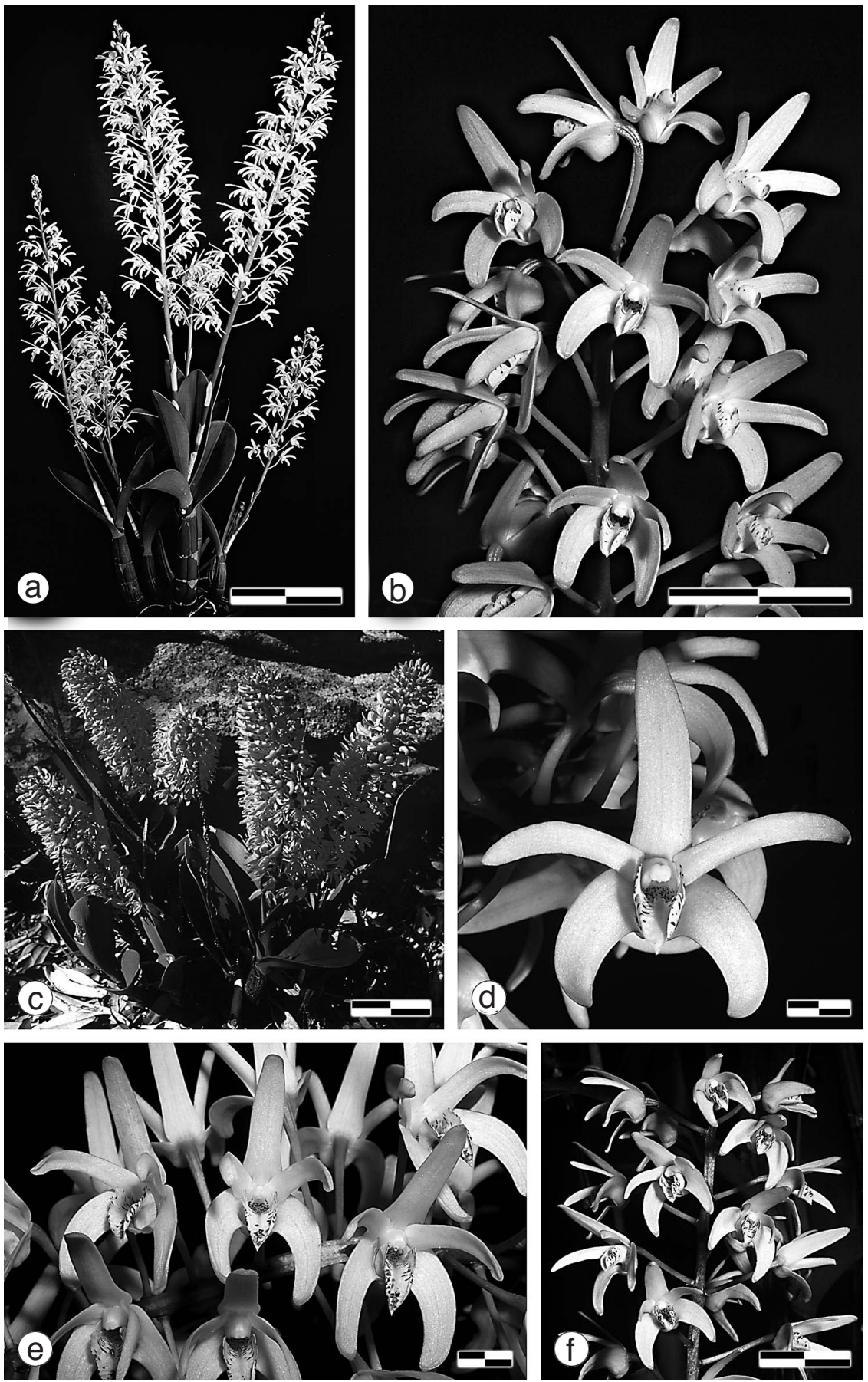

Fig. 16. Dendrobium speciosum var. capricornicum: (a) Rockhampton area; (b) north of Byfield. Dendrobium speciosum var. blackdownense: (c) densely flowered gold form; (e) open raceme form; (f) off white form. (d) Dendrobium speciosum var. carnarvonense, Carnarvon Gorge. Scale bars: (a), (c) $=10 \mathrm{~cm}$; (b), (f) $=5 \mathrm{~cm}$; (d), (e) $=1 \mathrm{~cm}$. 
$1.2-4.2 \mathrm{~cm}$ wide. Leaves terminal, erect and narrower in shorter forms, 2-4, 9-34 cm long, 5-11 cm wide, sub-elliptic to oblanceolate with a sheathing base, concave, rigid, 1-2.6 mm thick, relatively thin, large, and flexible in dense shade, relatively small and thick when exposed. Axes and leaves sometimes showing purple pigment in areas exposed to strong light. Racemes 1-3, 18-76 cm long; peduncle 8-29 cm long, 3-8 mm wide, shorter or no longer than the rachis, with 1-5 prominent bracts; rachis 10-48 cm long, with 9-125 star-like flowers openly spaced and displayed. Pedicel including ovary $2.5-5.3 \mathrm{~cm}$ long. Flowers usually opening widely, $3-5 \mathrm{~cm}$ long vertically, 3.3-5.5 cm wide horizontally, off white to cream, occasionally pale yellow, with purple spots or short bars marking the forelobe and midlobe of the labellum; tepals presenting with wide bases and heavy substance. Dorsal sepal 1.8-3.0 cm long, $0.55-0.9 \mathrm{~cm}$ wide at base, tapering from base to an obtuse-rounded apex. Lateral sepals $1.3-2.1 \mathrm{~cm}$ long, $0.7-1.0 \mathrm{~cm}$ wide at base, falcato-oblong, slightly incurved, obtuse at apex. Petals $1.6-2.7 \mathrm{~cm}$ long, $2-5 \mathrm{~mm}$ wide, almost linear, ending acutely at apex. Labellum $1.1-1.7 \mathrm{~cm}$ long, $1-1.3 \mathrm{~cm}$ wide; forelobe $0.7-1.0 \mathrm{~cm}$ long, $1-1.3 \mathrm{~cm}$ wide when flattened, incurved, subtriangular; midlobe on a short claw, $0.4-0.7 \mathrm{~cm}$ long, $0.6-1.0 \mathrm{~cm}$ wide when flattened, presenting as a curved channel with a short acute apex. Column c. $5 \mathrm{~mm}$ long, with a foot c. $6 \mathrm{~mm}$ long and at right angles to it. Mentum bifid, rounded, c. $7 \mathrm{~mm}$ long from ovary to apex. Callus raised, 2-ridged, low profiled, yellow to orange.

Flowering time: July-September, usually later than var. pedunculatum.

Distribution: Annan River, south to Mt Elliot (south of Townsville).

Etymology: the epithet alludes to the most northerly distribution of D. speciosum (Latin: boreale $=$ northern).

Notes: in Adams et al. (2006a) we reviewed D. speciosum var. curvicaule and showed it to be a name of uncertain application, and described var. boreale for plants north of $\mathrm{Mt}$ Elliot, which were previously attributed to var. curvicaule. Lithophytic or epiphytic in and around rainforest, very variable in plant size but commonly tall in densely shaded rainforest gullies, shorter plants lithophytic in more exposed sites and along rocky creeks with similar floral characters, often associated with small shrubs and moss beds. Occurs east of the Great Dividing Range from almost sea level to over 1200 metres. Plants may form dense colonies or be scattered. Tall rainforest forms and short forms are often only a few metres apart at the forest edges. Flowers are similar in both forms, and not greatly variable compared with other varieties.

There is a small degree of overlap with var. curvicaule in morphology and numerical characteristics. Dendrobium speciosum var. boreale is distinguished from typical var. pedunculatum in drier habitats, the latter having smaller pseudobulbs, shorter racemes and usually smaller flowers with more rounded segments.

In drier rainforest and sclerophyll forests e.g. Tinaroo Dam, Paluma, Bluewater, Mt Elliot, Hidden Valley and Tully areas, smaller plants show floral and vegetative characteristics that are intermediate in morphology between rainforest forms and var. pedunculatum. These forms are interpreted as shorter variants of var. boreale. The PCoA ordination indicates overlap between var. boreale and var. pedunculatum in a continuum (Fig. 4). The intermediate forms have variable peduncle length, from shorter to longer in relation to rachis. Axes of var. boreale are not significantly curved unless growing on vertical surfaces or in dense shade. 

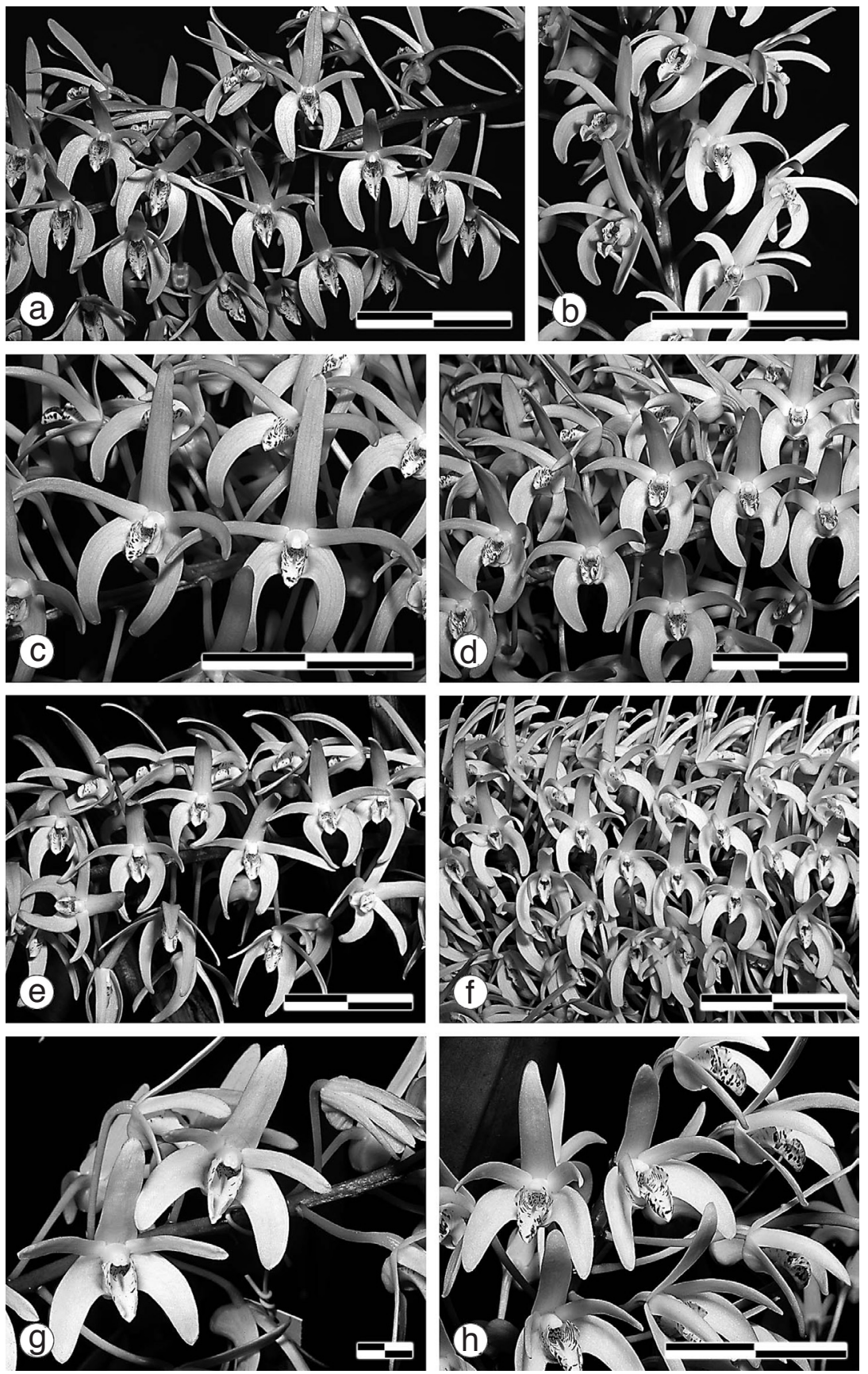

Fig. 17. Dendrobium speciosum: (a) var. boreale, cream flowers, Mt Finnigan, Queensland; (b) var. boreale, white flowers, Paluma, Queensland. (c) var. grandiflorum, gold form, Miriam Vale, Queensland; (d) var. curvicaule, Crediton, Queensland; (e) intermediate form from the boundary of var. grandiflorum and var. hillii territory, Blackbutt, south Queensland; (f) var. hillii, west of Wauchope, New South Wales; (g) var. pedunculatum, west of Mareeba, Queensland; (h) var. speciosum, Kangaroo Valley, New South Wales. Scale bars: (a)-(f), (h) $=5 \mathrm{~cm}$; (g) $=1 \mathrm{~cm}$. 
At Paluma and Hidden Valley some plants are shorter, $20-40 \mathrm{~cm}$, with narrower cylindrical axes and small rounded white flowers up to 90 per raceme. To the north there is a gradation towards the typical rainforest form of var. boreale, as the habitat becomes wetter and the rainforest canopy denser. Southwards to Townsville and beyond, where populations are more isolated and close to sea level, they may be diminutive with a less distinct or absent collum.

Dendrobium speciosum Sm. var. pedunculatum Clemesha, Orchadian 6: 261 (1981)

Plants variable, usually short, compact lithophytes without aerial roots. Leafbearing axes $4.1-36 \mathrm{~cm}$ long, $1.8-4.4 \mathrm{~cm}$ wide at midpoint, round to oval in cross section, collum usually absent, $1.2-3.7 \mathrm{~cm}$ wide at base, erect or mildly curving. Apex of axes usually narrowing to $1.1-2.7 \mathrm{~cm}$ wide. Leaves terminal, tending erect, 2-4, 6.3-19.3 cm long, 3.2-8.6 cm wide, leaf shape variable, sub-elliptic to ovate, relatively broad at the sheathing base, very coriaceous and rigid, concave, 1.1-2.5 $\mathrm{mm}$ thick. Axes and leaves exhibiting purple pigmentation in parts exposed to direct light. Racemes 1-2, 15.9-56.9 cm long, peduncle longer or shorter than the rachis, 8.4-30.7 cm long, 2.2-5.7 mm wide with small bracts; rachis 7.5-26.2 cm long, with 9-72 flowers, open or very closely spaced and overlapping forming a brush. Pedicel including ovary medium to very long, $1.9-4 \mathrm{~cm}$ long. Flowers usually opening widely or cupped, $2.8-4.5 \mathrm{~cm}$ long vertically, $3.1-4.7 \mathrm{~cm}$ wide horizontally, off-white to yellow segments of heavy substance, labellum white to cream, variously marked with purple spots or bars on forelobe and midlobe. Dorsal sepal $1.8-2.7 \mathrm{~cm}$ long, $0.45-0.78 \mathrm{~cm}$ wide at base, tapering from base to an obtuse-rounded apex. Lateral sepals $1.3-2.1 \mathrm{~cm}$ long, $0.7-1.1 \mathrm{~cm}$ wide, falcato-oblong and obtuse at apex. Petals $1.5-2.5 \mathrm{~cm}$ long, 2-3.8 mm wide at base, almost linear and ending acutely. Labellum $0.9-1.6 \mathrm{~cm}$ long, $0.9-1.3 \mathrm{~cm}$ wide, forelobe $0.6-0.9 \mathrm{~cm}$ long, $0.9-1.3 \mathrm{~cm}$ wide when flattened, incurved and subtriangular; midlobe on a short claw, $0.3-0.6 \mathrm{~cm}$ long, $0.65-1.0 \mathrm{~cm}$ wide when flattened, presenting as a curved channel with short acute apex. Column c. $5 \mathrm{~mm}$ long with a foot c. $6 \mathrm{~mm}$ long at right angles to it, mentum bifid, rounded, 6-7 mm long from ovary to apex. Callus raised, 2-ridged, low profiled, orange colour.

Flowering time: July-September.

Distribution: Parker River headwaters to Lumholz National Park, south of Atherton Tableland, representing a narrow strip of open forest. The distribution is smaller than previously considered, and habitat has been reduced by altered land use.

Notes: occurs on and to the west of the Great Dividing Range in northern Queensland. It includes some plants informally described as "var. compactum". Plants are scattered diffusely along rocky exposed watercourses, cliff faces and escarpments, and occasionally found on the base of small trees. Leaves tend to be very coriaceous, and may exhibit purple anthocyanin pigment. There is usually only one raceme per pseudobulb, which is apical, with well spaced (occasionally closely) pale cream to yellow flowers of heavy substance. The peduncle is often as long as or longer than the rachis, but forms are found with much shorter peduncles. 


\section{Variation of characters within and between varieties}

The variation in pseudobulb, leaf and flower length for plants assigned to varieties across the geographic range is presented in Figs 12-14, which provide the median, first to third interquartile range, and extremes in the data set. Other characters show similar patterns of continuous variation within and between described varieties.

\section{Distribution of Dendrobium speciosum in major regions of eastern Australia}

Our explorations indicate an almost continuous north to south distribution between the Annan River south of Cooktown (Queensland) and Genoa (eastern Victoria), with the qualification that small populations in marginal habitat may be up to $50 \mathrm{~km}$ apart. Small populations occur in locations previously considered to be unsuitable habitat. These include areas between Rockhampton and Gladstone, between Rockhampton and Sarina, and dry forests $100 \mathrm{~km}$ north and south of Townsville. We indicate the approximate limits of the varieties confirmed in this paper in Fig. 15.

Field surveys concentrated near the geographic limits of varieties revealed areas where populations exhibited characteristics intermediate between the two adjacent varieties. Within these populations we could not identify typical individuals of the varieties admixed with intermediate forms, or the presence of sporadic hybrids. Each population subtly varied from the next, forming an intergrade or continuum.

Between adjacent varieties along the Great Dividing Range there are plants with intermediate characters occupying territory generally less than $150 \mathrm{~km}$ apart. The following areas of intermediate forms were identified in relation to Fig. 1. There is a narrow zone between Regions $1 \mathrm{a}$ and $1 \mathrm{~b}$, between rainforest and dry, exposed cliff faces (var. pedunculatum-var. boreale interface). Between Regions 2 and 3, the interface between var. curvicaule and var. capricornicum, scattered populations occur in dry country. A narrow zone of populations with intermediate characteristics is recognized between Regions 3 and 5 (Mt Morgan area) at the var. capricornicum and var. grandiflorum interface. There is a broad zone of around $150 \mathrm{~km}$ between Regions 5 and 6, which extends north from a line between Mt Mee and Crows Nest, and includes Blackbutt, Gallangowan, Conondale and Kilkivan. This represents the var. grandiflorum and var. hillii interface. Between Regions 6 and 7, the interface between var. hillii and var. speciosum forms a band between Bulahdelah and Barrington Tops, which extends south-west to Munghorn Gap near Mudgee.

\section{Discussion}

\section{Interpretation of analyses}

This extensive study of variation indicates that D. speciosum is a single variable species differing mainly in size characteristics, occurring in widely varied habitats. There are intergrading groups best interpreted as varieties, and no discrete qualitative differences between any populations or regions. Some plants do not fit exactly with any varietal description and are most satisfactorily designated by geographical notation. Based on UPGMA cluster analysis, the most distinct varieties are var. boreale (Region 1a) and var. hillii (Region 6). 
The variation within this species complex indicates morphological forms with a geographic pattern that is largely allopatric. Multivariate analyses of D. speciosum could not demonstrate a phenetic gap between any identified groups, all of which overlapped in ordination space to varying degrees. Plants described as varieties may overlap in ordination space, but in the areas of interface between two varieties they are not identifiable as admixtures with intervarietal hybrids. These populations consist of plants which all show intermediate characteristics.

The addition of plants from newly surveyed areas, and interpretations of groups as three new varieties, one in northern Queensland and two in central Queensland, has expanded the recognised level of variation. The areas of greatest complexity and most difficult interpretation occur in north Queensland, and central Queensland along the Tropic of Capricorn, as demonstrated in the regional ordinations (Figs 4-6).

\section{Distribution of Taxa}

The distributional range of taxa within D. speciosum has been difficult to define due to wide inherent variation, zones of intermediate forms, and significant loss of habitat, particularly at the var. speciosum/ var. hillii and var. hillii/ var. grandiflorum interfaces. For the six most northerly varieties our surveys have clarified the distributions. Habitat loss is not confounding, except at the interface of var.pedunculatum and var. boreale on the Atherton Tableland.

The distribution is much more continuous than previously considered, especially north of Rockhampton. The gradation between var. curvicaule and var. capricornicum between Clairview and Byfield represents the largest north-south zone of intermediates. The more southerly intermediate zones between var. grandiflorum and var. hillii, and between var. hillii and var. speciosum have been noted by previous reviewers, who have highlighted the difficulty of assigning these plants to varieties. Gregory (1988) noted that varieties "gradually merge into one another up and down the Great Dividing Range". Jones (1988 p. 478) stated that "confusing intermediate forms may occur where ranges (of varieties) overlap". Dockrill (1992, vol. 1 p.457) noted that "all varieties within themselves are quite variable, and merging of intermediates.... made it virtually impossible to give a satisfactory determination of a particular clone." Banks and Clemesha (1990) noted intermediate areas where it was "difficult to say where one stops and another starts".

For the var. hillii and var. speciosum interface, the intermediate zone requires more exploration at the western limit. There has been considerable habitat loss and plant collection, especially south of the Hunter River. Reports of plants attributed to var hillii from Peat's Ridge (Clemesha 1986), and from the Wattagan area, cannot be conclusively evaluated. Our recent surveys on the coastal ranges south of Newcastle, including the Wattagan Mountains, indicated only plants attributable to var. speciosum. 


\section{Biogeography}

In north Queensland, medium to large plants of var. boreale have the largest distribution, in wet tropical rainforest (Region 1a). In Region 1a there are also shorter forms of var. boreale, usually in intermediate sclerophyll forest habitat on margins of rainforest. In the dry zone north and south of Townsville, shorter plants attributed to var. boreale are found in small isolated populations, and a similar plant form is found in isolated colonies between Sarina and Rockhampton.

Variety pedunculatum is a short plant form occupying a very narrow strip of dry country on or west of the Great Divide, on the fringe of var. boreale territory, from west of the Windsor Tableland to Lumholz National Park (Region 1b). The distribution area of var. pedunculatum is extremely small in relation to that of var. boreale (Fig. 15). The type form of var. pedunculatum from Bone's Knob is in this narrow strip, and one of the major clarifications of this study is the designation of shorter plants east of the divide in and around rainforest as variants of var. boreale. Many of these were previously regarded as forms of var. pedunculatum. They are usually differentiated by long upright racemes with many small to medium sized white or pale cream flowers which have wide segments, and their peduncles are variable, often short in relation to rachis length.

On volcanic plugs near Rockhampton, short plants meeting the description of var. capricornicum (Clemesha 1982) intergrade with forms similar to those in the southern area of Region 2 (var. curvicaule). West to Blackdown Tableland and Carnarvon Gorge, two new taxa are described on the basis of morphological characteristics and regional PCoA analyses, var. blackdownense and var. carnarvonense. These groups abut in ordination space and are geographically distinct, with a small amount of overlap in numerical analyses with plants of Regions 2, 3 and 5 (Figs 3, 5 and 6). Clemesha (1982) and Walsh (2000) commented that some plants of var. capricornicum may resemble var. grandiflorum. We consider from repeated observations that var. carnarvonense and var. blackdownense are clearly distinguishable from var. grandiflorum.

In Region 5, primarily consisting of var. grandiflorum, there is a fairly abrupt narrow interface between var. capricornicum and var. grandiflorum in the north, determined by a limit of moister rainforest south of Rockhampton. There is a considerable gradation between var. grandiflorum and var. hillii at the boundary of Regions 5 and 6, the var. grandiflorum at the southern limit being usually shorter in stature, with smaller flowers. Around Gladstone, tall forms in dry rainforest and shorter forms on volcanic plugs are found with large gold flowers.

Plants of Regions 7 and 8 (var. speciosum) are easily identified by their locality, but overlap considerably with populations from other regions in the ordination (Fig. 3). Skilled observers are usually able to identify them from their vegetative and floral form, except for the area of intermediate forms at the var. speciosum and var. hillii interface. The associations of populations with habitat assist in designation of varieties in Region 1 and on the volcanic plugs of Region 3 (Table 4), and suggests that much of the variation is ecophenetic. 
Table 4. Associations of varieties with habitat in regions.

$\begin{array}{llccc}\text { Region } & \text { Variety } & \text { Rainforest } & \text { Sclerophyll Forest, or Riparian } & \text { Rocky Plugs } \\ 1 \mathrm{a} & \text { boreale } & + & + & - \\ 1 \mathrm{~b} & \text { pedunculatum } & - & + & - \\ 2 & \text { curvicaule } & + & + & - \\ 3 & \text { capricornicum } & - & + & + \\ 4 & \text { blackdownense } & - & + & - \\ 4 & \text { carnarvonense } & - & + & + \\ 5 & \text { grandiflorum } & + & + & - \\ 6 & \text { hillii } & + & + & - \\ 7,8 & \text { speciosum } & + & & +\end{array}$

\section{Recommended taxonomy}

There are no generally accepted criteria or definitions for grouping or ranking in botanical taxonomy, especially at specific and infraspecific level. Subspecies, varieties, subvarieties and forms have been used in many ways to interpret degrees of difference. More recent practice has tended to treat intergrading taxa, and even subgroupings within some clines, as subspecies. Stuessy (1990, p. 193) attempted to define levels of difference for subspecies, varieties and forms, and recommended that existing ranks be retained in the interest of nomenclatural stability for groups with a history of taxonomic study, and that subspecies could be preferred for newly studied groups. Choice of rank remains an individual decision of taxonomists based on their understanding of a group.

In taxonomic studies of Dendrobium, Schlechter (1982) arranged individual species as naturally as possible within the genus, and did not provide a species definition. Dockrill $(1969,1992)$ discussed the difficulties of interpretation of sub specific taxa and species, questioning the proposals of Clements (1989) to upgrade varieties to species, and disputing the proposal to elevate varieties of $D$. speciosum. He considered it important to take into account similarities as well as differences (Dockrill 1995). We have found no clear-cut qualitative differences between regional subgroups of $D$. speciosum, with the possible exception of the earlier but still variable flowering time for D. speciosum var. capricornicum, and thus have not used specific rank, as proposed by Clements (1989) and Clements and Jones (2002). In this study we experienced difficulty in defining taxa in a large data set encompassing all major variation, even with numerical techniques that maximise separation.

The following reasons are advanced for the decision to interpret the variation as representing varieties in a species complex.

1. We understand the species as having a clinal or continuum of variation, with features running north-south along the Great Dividing Range, and east-west along the Tropic of Capricorn. We describe nine sub taxa within the species, but within each there are atypical forms and considerable infra taxa variation, all characters varying continuously over the geographic range. We could find no convincing evidence to support the interpretation of taxa at specific level. 
2. Analyses and observations did not demonstrate any qualitative differences for any sub group. This interpretation is in accord with the view of Stuessy (1990) that varieties may have one to few conspicuous differences, and subspecies several differences. Bayly and Kellow (2006) have made similar distinctions in their use of subspecies and varieties for Hebe Jussieu.

3. All subgroups overlap to a significant extent in ordinations.

4. Near the geographic limits of varieties there are populations of plants identifiable as intermediates.

5. Despite disjunct distributions we found that var. carnarvonense and var. blackdownense have a similar level of differences from other varieties, and consider they are best regarded as varieties.

6. A satisfactory key to groups cannot be constructed, even for $70 \%$ (estimated) of plants, similar to the opinion of Dockrill (1992).

7. The rank of variety maintains nomenclatural stability for a species with a long history of description and classification. Dendrobium speciosum is one of the most spectacular horticultural plants and a species widely discussed by orchid taxonomists and enthusiasts. There is a need for infraspecific classification to aid communication concerning variation over a very large distribution range. The rank of variety has been effective for communication, and we concur with the guidelines proposed by Entwisle and Weston (2005) of minimal taxonomic change, especially in plant groups of high interest.

A summary of the proposed taxonomy for D. speciosum is presented in Table 7. Examples of varieties and forms illustrated in Figs 16 and 17 represent a small part of the total variation in plant and floral characteristics in the respective regions.

Table 7. Taxonomic nomenclature for Dendrobium speciosum.

\section{Region No.}

1.

2.

3.

4.

5.

6.

7.

8.

Region
North Queensland
Whitsunday
East Capricorn
(central Queensland)

West Capricorn (central Queensland)

Southern Queensland

Southern Queensland and Northern New South Wales

Southern New South Wales

Far south New South Wales to Victoria
Taxa

var. boreale var. pedunculatum

var. curvicaule

var. capricornicum

atypical individuals and populations intermediate between var. capricornicum and var. curvicaule, and var. capricornicum and var. grandiflorum specified by locality

var. blackdownense var. carnarvonense

var. grandiflorum intermediates with var. hillii specified by locality

var. hillii

intermediates with var. speciosum specified by locality

var. speciosum

var. speciosum

-

(a) 
Most of the plants of var. hillii fit Masters' (1877) description, except at the distribution limits. Plants from eastern Victoria to the Hunter River form a cohesive group that can be ascribed to var. speciosum. Dendrobium speciosum var. grandiflorum is useful to refer to plants between southern Queensland and the Gladstone area, but at the southern boundary with var. hillii, intermediates are shorter with smaller flowers, and require a locality designation.

Plants of central Queensland may meet descriptions of var. capricornicum in the east on some volcanic plugs, but others in forest and on other plugs form a variable group. This finding extends the field observations made by Walsh (2000). He noted a resemblance of floral characteristics to var. grandiflorum, in particular the gold flower colour. Clemesha (1981a) described some west Capricorn plants as a dwarf race of var. grandiflorum. Our analyses do not support a close relationship to var. grandiflorum. The Carnarvon plants have shorter, curving robust pseudobulbs like var. speciosum, but clearly differ in floral characteristics consistent with a separate entity.

\section{Taxonomic approaches in Australian Orchidaceae}

The purpose of all classificatory systems is to advance the understanding of individuals, their variation and relationships, and to promote ease of communication when discussing them. Orchids are a difficult taxonomic group, and Australian orchids with large distributions over diverse habitat pose particular problems in achieving adequate sampling for assessment of their variation, and consideration of taxonomic rank. We contend that several dendrobiums, including D. speciosum and D. kingianum, are species complexes with various levels of continuous and sometimes discontinuous variation (Adams et al. 2006b). Within these complexes there may be sub groupings which intergrade and cannot be easily differentiated. If a complex is not optimally sampled, sub groups may appear to represent distinct taxa.

Subjective assessment of gross morphology is difficult in these complexes, as noted in the early phases of classificatory systems of Locke, Ray, du Buffon, Linnaeus (Huxley 2003). Non-morphological methods such as biochemistry and DNA analyses could be used to form a data set for analysis and interpretation to recognise taxa. At the infraspecific level, these may be limited in usefulness or practicality. For D. speciosum we have found that all varieties are compatible in cross pollination, giving rise to inter varietal seedlings; bee pollination was not variety specific (Adams 1991, Adams \& Lawson 1993), and fragrance biochemistry did not provide useful taxonomic characters (Adams 1991). An alternative approach for users is to specify plants by their original location, or to use ordination and other numerical representations as has been proposed for infraspecific taxa by Prentice (1986).

Species complexes like D. speciosum are best categorised by considering the full range of variation and accurately describing similarities and partial differences between populations. Intermediates and atypical variants must be described as such, and not ignored or categorised arbitrarily. The value of naming systems, given their inherent limitations, is appreciated in how effectively they establish conventions for communication and development of ideas (Pearson 2001). 


\section{Acknowledgments}

State National Parks and Wildlife Services allowed access to plants for this study. We thank Prof. Pauline Ladiges for constructive comments on earlier drafts of the manuscript, and Dr Jim Ross and Neville Walsh (National Herbarium, Royal Botanic Gardens, Melbourne) for assistance with taxonomy and Latin diagnosis. Stuart Gardner provided technical assistance. Peter Weston contributed helpful discussions and comments.

\section{References}

Adams PB (1991) Variation, multiple pollinators and breeding system in Dendrobium speciosum Smith : A biological review. Orchadian 10: 124-140.

Adams PB, Burke JM \& Lawson SD (2006a) Dendrobium speciosum Sm., Sect. Dendrocoryne: Orchidaceae in North Queensland, numerical taxonomy and descriptions of two taxa. Australian Systematic Botany (2006 in press).

Adams PB, Burke JM \& Lawson SD (2006b) Systematic analysis of Dendrobium Schwartz section Dendrocoryne in the Australian region. Plant Systematics and Evolution (2006 in press).

Adams PB \& Lawson SD (1993) Pollination in Australian orchids: A critical assessment of published reports 1882-1992. Australian Journal of Botany 41: 553-75.

Bailey FM (1896) Contributions to the Queensland Flora. Botany Bulletin, Department of Agriculture, Queensland 14:12.

Banks DP \& Clemesha SC (1990) Dendrobium speciosum : a review of the species. Australian Orchid Review 55: 4-14.

Bayly MJ \& Kellow AV (2006) An Illustrated Guide to New Zealand Hebes. (Te Papa Press: Wellington)

Belbin L (1988) 'PATN Analysis Package', CSIRO Division of Wildlife and Rangeland Research, Canberra, Australia.

Burke JM (1998) A numerical analysis of Dendrobium speciosum Smith and section Dendrocoryne (Orchidaceae). (Unpublished MSc Thesis: James Cook University of North Queensland)

Burke JM \& Adams PB (2002) Variation in the Dendrobium speciosum (Orchidaceae) complex: a numerical approach to the species problem. Australian Systematic Botany 15: 63-80.

Clements MA (1989) Catalogue of Australian Orchidaceae. Australian Orchid Research 1: 1-62.

Clements MA \& Jones DL (2002) Nomenclatural changes in the Dendrobieae (Orchidaceae) 1: The Australasian region. Orchadian 13: 485-497.

Clemesha SC (1981a) A review of Dendrobium speciosum Sm. Orchadian 6: 247-262.

Clemesha SC (1981b) Dendrobium speciosum var. bancroftianum. Orchadian 6: 271-272.

Clemesha SC (1982) A new variety of Dendrobium speciosum Smith from Central Queensland. Orchadian 7: 103-106.

Clemesha SC (1986) Dendrobium speciosum - an update. Orchadian 8: 173-178.

Crisp MD \& Weston PH (1993) Geographic and ontogenetic variation in morphology of Australian Waratahs (Telopea: Proteaceae). Systematic Biology 42: 49-76.

Dockrill AW (1969) Australian Indigenous Orchids, vol. 1. (Society for Growing Australian Plants: Sydney)

Dockrill, AW (1992) Australian Indigenous Orchids, vol. 1, 2nd edition. (Surrey Beatty and Sons Pty. Ltd., Chipping Norton)

Dockrill AW (1995) Some thoughts on taxa and taxonomic categories (particularly species) of orchids. Orchadian 11: 292-294.

Entwisle TJ \& Weston P (2005) Majority rules, when systematists disagree. Australian Systematic Botany 18: 1-6.

Gould SJ \& Johnston RF (1972) Geographic variation. Annual Review of Ecology and Systematics 3: 457-98. 
Gower JC (1966) Some distance properties of latent root and vector methods used in multivariate analysis. Biometrika 53: 325-338.

Gregory T. (1988) Some thoughts on Dendrobium speciosum. Australian Orchid Review 53: 1726.

Grundon NJ, Wallace BJ \& Harrison M (1990) Review: M. A. Clements Catalogue of Australian Orchidaceae. Orchadian 9: 287-92.

Hooker W (1861) Dendrobium hillii. Curtis's Botanical Magazine 87: t. 5261.

Huxley R (2003) Challenging the dogma: classifying and describing the natural world. Pp. 70-79 in Sloan K (ed.) Enlightenment. (The British Museum Press: London)

Jones DL (1988) Native Orchids of Australia. (Reed Books: Frenchs Forest)

Lavarack PS (1991) An appraisal of the species concept in the taxonomy of Australian orchids. Orchadian 10: 141-43.

Lavarack PS \& Gray B (1985) Tropical Orchids of Australia. (Thomas Nelson: Melbourne)

Masters MT (1877) Dendrobium speciosum var. hillii. Gardener's Chronicle (new ser.) 7: 112, f. 18.

Milligan GW \& Cooper MC (1988) A study of standardisation of variables in cluster analysis. Journal of Classification 5: 181-204.

Pearson H (2001) Biology's name game. Nature 411: 631-632.

Prentice HC (1986) Continuous variation and classification. Pp. 21-32 in Styles BT (ed.) Infraspecific Classification of Wild and Cultivated Plants. (Oxford University Press: New York)

Schlechter R (1982) The Orchidaceae of German New Guinea. (The Australian Orchid Foundation: Melbourne)

Smith JE (1804) Exotic Botany vol. 1: 17, t.10 (R. Taylor \& Co.: London)

Sneath PHA \& Sokal RH (1973) Numerical Taxonomy: The Principles and Practice of Numerical Classification. (WH Freeman and Co.: San Francisco)

Stuessy TF (1990) Plant Taxonomy. (Columbia University Press: New York)

Upton WT (1989) Dendrobium Orchids of Australia. (Houghton Mifflin: Australia)

Walsh G (2000) A bit about the rock orchids (Dendrobium speciosum complex) of Capricornia. Orchadian 13: 210-215.

Williams WT (1975a) Hierarchical agglomerative strategies. Pp. 84-90 in Williams WT (ed.) Pattern Analysis in Agricultural Science. (CSIRO \& Elsevier Scientific Publishing Company: Amsterdam)

Williams WT (1975b) Other Ordination Procedures. Pp. 59-75 in Williams WT (ed.) Pattern Analysis in Agricultural Science. (CSIRO \& Elsevier Scientific Publishing Company: Amsterdam)

Manuscript received October 2005, accepted 17 February 2006 